NIST Technical Note 2184

\title{
The Design and Performance of a Second-Generation Phi Meter
}

\author{
Ryan Falkenstein-Smith \\ Thomas Cleary
}

This publication is available free of charge from: https://doi.org/10.6028/NIST.TN.2184

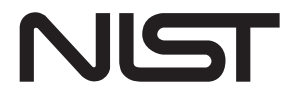

National Institute of Standards and Technology

U.S. Department of Commerce 


\title{
The Design and Performance of a Second-Generation Phi Meter
}

\author{
Ryan Falkenstein-Smith \\ Thomas Cleary \\ Fire Research Division \\ Engineering Laboratory
}

This publication is available free of charge from: https://doi.org/10.6028/NIST.TN.2184

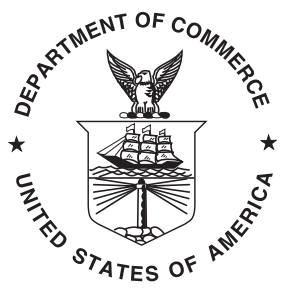

U.S. Department of Commerce Gina M. Raimondo, Secretary

National Institute of Standards and Technology James K. Olthoff, Performing the Non-Exclusive Functions and Duties of the Under Secretary of Commerce for Standards and Technology \& Director, National Institute of Standards and Technology 
Certain commercial entities, equipment, or materials may be identified in this document in order to describe an experimental procedure or concept adequately. Such identification is not intended to imply recommendation or endorsement by the National Institute of Standards and Technology, nor is it intended to imply that the entities, materials, or equipment are necessarily the best available for the purpose.

National Institute of Standards and Technology Technical Note 2184

Natl. Inst. Stand. Technol. Tech. Note 2184, 39 pages (January 2022) CODEN: NTNOEF

This publication is available free of charge from: https://doi.org/10.6028/NIST.TN.2184 


\begin{abstract}
This report documents the design and performance of a second-generation phi meter used in multi-scale experimental applications. A constructed second-generation phi meter is implemented in bench and $2 / 5^{\text {th }}$ scale experiments to demonstrate the instrument's ability to conduct global and local equivalence ratio measurements and gas species concentrations of combustion products (i.e., carbon dioxide, water vapor, and oxygen) without knowledge of the sampled fuel composition. Bench-scale experiments evaluated the second-generation phi meter's functionality by introducing known fuel-air ratios into the instrument and verifying measurements via the carbon to hydrogen ratio and mass balance. The bench-scale experiments selected methane, propane, and propene as the fuels of interest. The $2 / 5^{\text {th }}$ scale experiments implemented two second-generation phi meters in a series of $25 \mathrm{~kW}$ methane backdraft experiments. Backdraft experiments provided an ideal setting to test the phi meter's performance by subjecting the instrument to a transient heterogeneous gas mixture. The phi meters' sampling location was positioned such that the extracted gas samples fed into the instrument were unknown. Global and local equivalence ratio measurements made in the $2 / 5^{\text {th }}$ scale compartment were compared to independent gas analyzer and gas chromatograph measurements. In the bench-scale experiments, the global equivalence ratio, water vapor concentration, and carbon to hydrogen ratio measurements are in fair agreement with their expected values. Real-time global and local equivalence ratio and carbon to hydrogen ratio measurements obtained during a backdraft experiment were observed to increase as the fuel concentration within the $2 / 5^{\text {th }}$ scale compartment increased. Real-time global and local equivalence ratios were verified by the independent instrumentation.
\end{abstract}

\title{
Key words
}

Global equivalence ratio; Gas extraction sampling; Local equivalence ratio; Phi meter. 


\section{Table of Contents}

1 Introduction 1

1.1 The Global and Local Equivalence Ratio 1

2 A Second-Generation Phi Meter Design and Operation 3

3 Experimental Setup $\quad 5$

3.1 Bench-scale Experiments 5

3.2 Backdraft Experiments 8

4 Results and Discussion $\quad 11$

4.1 Bench-scale Experiments $\quad 11$

4.2 Backdraft Experiments 16

5 Conclusion $\quad 19$

References $\quad 20$

A Photos of constructed second-generation phi meter 22

B Uncertainty Analysis of Second-Generation Phi Meter Measurements 28

B.1 Global Equivalence Ratio 28

B.2 Water Vapor Flow in the Reactor's Exhaust 29

B.3 Carbon to Hydrogen Ratio 29

B.4 Mass Balance 29

B.5 Local Equivalence Ratio 30

C Derivation of Local Equivalence Ratio Measurement via Phi Meter 31

D Uncertainty Analysis of Additional Gas Species Concentration Measurements 32 


\section{List of Tables}

Table B.1 List of uncertainties for selected phi meter components. 28

Table D.1 List of uncertainties for gas analyzer components. 


\section{List of Figures}

Fig. 1 Schematic of the second-generation phi meter 4

Fig. 2 Comparison of soot filters positioned at the inlet and outlet of the phi meter's reactor when subjected to $80 \mathrm{mg} / \mathrm{m}^{3} \pm 5 \mathrm{mg} / \mathrm{m}^{3}$ for $1 \mathrm{~min} \quad 6$

Fig. 3 Experimental setup for bench-scale experiments 7

Fig. 4 Schematic of gas sampling techniques in backdraft experiments 9

Fig. 5 Time-averaged global equivalence ratio measurements compared to expected values

Fig. 6 Time-averaged volumetric flow of water vapor measurements compared to expected values

Fig. 7 Time-averaged carbon to hydrogen ratio measurements calculated across a range of global equivalence ratios

Fig. 8 Time-averaged ratios of mass flow measurements calculated across a range of global equivalence ratios

Fig. 9 Real-time global equivalence ratio measurements from the upper and middle section of the compartment during a backdraft experiment

Fig. 10 Real-time local equivalence ratio measurements from the upper and middle section of the compartment during a backdraft experiment

Fig. 11 Real-time carbon to hydrogen measurements from the upper and middle section of the compartment during a backdraft experiment

Fig. 12 Time-Averaged global equivalence ratio measurements from the upper and middle section of the compartment during a backdraft experiment

Fig. 13 Time-Averaged local equivalence ratio measurements from the upper and middle section of the compartment during a backdraft experiment

Fig. A.1 Front and side view photograph of the second-generation phi meter.

Fig. A.2 Photograph of the internal components in the second-generation phi meter. 23

Fig. A.3 Photograph of internal furnace components in the second-generation phi meter's inlet and reactor configuration

Fig. A.4 Side view photograph of components in the second-generation phi meter's outlet.

Fig. A.5 Photograph of HTMFC components 26

Fig. A.6 Rear view photograph of the second-generation phi meter 27 


\section{Introduction}

Ventilation (i.e., the availability of oxygen, $\mathrm{O}_{2}$ ) is an essential component to understanding fire dynamics within an enclosure. Limited oxygen within an enclosure can significantly affect the risk enclosure fires pose, particularly with the generation of carbon monoxide. Ventilation within an enclosure can be estimated from the equivalence ratio defined as the mass ratio of fuel to entrapped air within a control volume normalized by the stoichiometric ratio of the fuel.

Several techniques have been used to measure the equivalence ratio from combustion processes. Applications of molecular spectroscopy, such as laser-induced fluorescence (LIF) and laser-induced breakdown spectroscopy (LIBS), are shown to measure the equivalence ratio using non-extractive techniques [1-5] and require extensive corrections to address low signal to noise ratios. Using an extractive sampling approach, gas chromotography with mass selectivity detectors can provide a time-averaged equivalence ratio [6-9]. For real-time applications, a phi meter, initially proposed by Babrauskas et al. [10], has been utilized for several applications [11-17] to make in-situ global equivalence ratio measurements. In previous works, the global equivalence ratio has been observed to correlate with species production rates and yields [18-22] which aid in assessing the risk of an enclosure fire.

The purpose of this report is to demonstrate the design and performance of a secondgeneration phi meter capable of conducting real-time simultaneous global and local equivalence ratio measurements without knowledge of the sampled fuel composition. The secondgeneration phi meter improves upon its predecessor's design by its novel ability to conduct global and local equivalence ratio measurements simultaneously with combustion product concentrations which provide additional insight into the extracted gas sample composition. The second-generation phi meter was implemented in a series of bench-scale and $2 / 5^{\text {th }}$ scale combustion experiments of which time-averaged and real-time equivalence ratio measurements were made, respectively. In both series, the second-generation phi meter was subjected to a wide range of heterogeneous gas mixtures, of which the equivalence ratio measurements illustrate the robust functionality of the instrument.

\subsection{The Global and Local Equivalence Ratio}

The global equivalence ratio, in comparison to the local equivalence ratio, can have significant utility in understanding the ventilation within an enclosure. The global equivalence ratio, $\phi_{\mathrm{G}}$, is defined from the mass flow ratio of combusted and uncombusted air and fuel within a control volume. The local equivalence ratio, $\phi_{\mathrm{L}}$, is defined from the mass flow of uncombusted air and fuel within a control volume.

A clear distinction between $\phi_{\mathrm{G}}$ and $\phi_{\mathrm{L}}$ can be made when considering a gas sample extracted from a fire plume entrapped in an enclosure. Initially, in the presence of an ignition source, a flammable and presumably well-mixed fuel and air mixture combusts inside the compartment generating carbon dioxide, $\mathrm{CO}_{2}$, water vapor, $\mathrm{H}_{2} \mathrm{O}$, and excess fuel or air depending on whether the combusted gas mixture was fuel-rich or fuel-lean, 
respectively. Assuming under-ventilated fire, the reaction of a fuel-rich mixture is shown below, where $\dot{\mathrm{a}}$ and $\dot{\eta}\left(\mathrm{x}+\frac{\mathrm{y}}{4}-\frac{\mathrm{z}}{2}\right)$ are the molar flow rates of fuel and air, respectively. Note that the molar flow rate of air is defined as the product of a molar flow coefficient, $\dot{\eta}$, and a stoichiometric coefficient $\left(x+\frac{y}{4}-\frac{z}{2}\right)$, where $x, y$, and $z$ are the number of carbon, hydrogen, and oxygen atoms in the parent fuel. The molar flow rate of air is defined as such to simplify the equivalence ratio definitions since the stoichiometric coefficient will cancel out in Eqs. 8 and 9.

$$
\begin{aligned}
\dot{\mathrm{a}} \mathrm{C}_{\mathrm{x}} \mathrm{H}_{\mathrm{y}} \mathrm{O}_{\mathrm{z}} \mathrm{N}_{\alpha}+\dot{\eta}\left(\mathrm{x}+\frac{\mathrm{y}}{4}-\frac{\mathrm{z}}{2}\right)\left(\mathrm{O}_{2}+3.74 \mathrm{~N}_{2}+0.0445 \mathrm{Ar}\right) \rightarrow \\
\quad(\dot{\mathrm{a}}-\dot{\eta}) \mathrm{C}_{\mathrm{x}} \mathrm{H}_{\mathrm{y}} \mathrm{O}_{\mathrm{z}} \mathrm{N}_{\alpha}+\dot{\eta} \mathrm{x} \mathrm{CO}_{2}+\dot{\eta} \frac{\mathrm{y}}{2} \mathrm{H}_{2} \mathrm{O}+ \\
\quad\left(3.74 \dot{\eta}\left(\mathrm{x}+\frac{\mathrm{y}}{4}-\frac{\mathrm{z}}{2}\right)+\frac{\dot{\eta} \alpha}{2}\right) \mathrm{N}_{2}+\left(0.0445 \dot{\eta}\left(\mathrm{x}+\frac{\mathrm{y}}{4}-\frac{\mathrm{z}}{2}\right)\right) \mathrm{Ar}
\end{aligned}
$$

Since the reaction assumes an initial rich mixture, $\dot{\eta}\left(\mathrm{x}+\frac{\mathrm{y}}{4}-\frac{\mathrm{z}}{2}\right)$ can be defined as combusted air. Also note that this reaction assumes that all carbon and hydrogen are converted to $\mathrm{CO}_{2}$ and $\mathrm{H}_{2} \mathrm{O}$. In reality, the combustion products would also consist of intermediate species, such as carbon monoxide, $\mathrm{CO}$, hydrogen, $\mathrm{H}_{2}$, and soot. This reaction also neglects all other air components, including water vapor.

After the initial combustion in the compartment, the hot gas mixture can react with uncombusted air, $\dot{\varepsilon}\left(\mathrm{x}+\frac{\mathrm{y}}{4}-\frac{\mathrm{z}}{2}\right)$, eventually accumulating into a gas mixture of air, $\mathrm{CO}_{2}$, and $\mathrm{H}_{2} \mathrm{O}$, as shown in Eq. 2.

$$
\begin{aligned}
(\dot{\mathrm{a}}-\dot{\eta}) \mathrm{C}_{\mathrm{x}} \mathrm{H}_{\mathrm{y}} \mathrm{O}_{\mathrm{z}} \mathrm{N}_{\alpha}+\dot{\varepsilon}\left(\mathrm{x}+\frac{\mathrm{y}}{4}-\frac{\mathrm{z}}{2}\right)\left(\mathrm{O}_{2}+3.74 \mathrm{~N}_{2}+0.0445 \mathrm{Ar}\right) & \\
& +\dot{\eta} \mathrm{x} \mathrm{CO}_{2}+\dot{\eta} \frac{\mathrm{y}}{2} \mathrm{H}_{2} \mathrm{O}+\left(3.74 \dot{\eta}\left(\mathrm{x}+\frac{\mathrm{y}}{4}-\frac{\mathrm{z}}{2}\right)+\frac{\dot{\eta} \alpha}{2}\right) \mathrm{N}_{2} \\
& +\left(0.0445 \dot{\eta}\left(\mathrm{x}+\frac{\mathrm{y}}{4}-\frac{\mathrm{z}}{2}\right)\right) \mathrm{Ar} \rightarrow \\
& \dot{\mathrm{b}} \mathrm{O}_{2}+\dot{\mathrm{c}} \mathrm{CO}_{2}+\dot{\mathrm{d}} \mathrm{H}_{2} \mathrm{O}+\dot{\mathrm{e}} \mathrm{N}_{2}+\dot{\mathrm{f}} \mathrm{Ar}
\end{aligned}
$$

where

$$
\begin{gathered}
\dot{\mathrm{c}}=\dot{\mathrm{a}} \mathrm{x} \\
\dot{\mathrm{d}}=\frac{1}{2} \dot{\mathrm{a}} \mathrm{y} \\
\dot{\mathrm{b}}=(\dot{\mathrm{a}}-\dot{\eta}-\dot{\varepsilon})\left(\mathrm{x}+\frac{\mathrm{y}}{4}-\frac{\mathrm{z}}{2}\right) \\
\dot{\mathrm{e}}=3.74(\dot{\eta}+\dot{\varepsilon})\left(\mathrm{x}+\frac{\mathrm{y}}{4}-\frac{\mathrm{z}}{2}\right)+\frac{\alpha}{2}(\dot{\eta}+(\dot{\mathrm{a}}-\dot{\eta})) \\
\mathrm{f}=0.0445(\dot{\eta}+\dot{\varepsilon})\left(\mathrm{x}+\frac{\mathrm{y}}{4}-\frac{\mathrm{z}}{2}\right)
\end{gathered}
$$


If a portion of combustion products from Eq. 2 are extracted, the local equivalence ratio is defined by the uncombusted fuel and air of the extracted sample at the location within the compartment it was extracted.

$$
\phi_{\mathrm{L}}=\frac{(\dot{\mathrm{a}}-\dot{\eta})}{\dot{\varepsilon}}
$$

The global equivalence ratio is defined by the combusted and uncombusted fuel and air of the same extracted gas sample at the same location within the compartment.

$$
\phi_{\mathrm{G}}=\frac{\dot{\mathrm{a}}}{\dot{\varepsilon}+\dot{\eta}}
$$

\section{A Second-Generation Phi Meter Design and Operation}

Figure 1 presents a schematic of a second-generation phi meter. Photos of the constructed second-generation phi meter are provided in Appendix A. During operation, gas samples are extracted into the phi meter via vacuum pump positioned at the end of the instrument's sampling line. Upon extraction, gas samples are fed into the phi meter's reactor enclosed in a high-temperature tubular furnace. The phi meter's reactor includes quartz tubing packed with a combustion catalyst, heated to approximately $900^{\circ} \mathrm{C}$. In this work, platinum-coated silica beads (Sigma-Aldrich/Millipore Sigma 520691 ${ }^{1}$ ) were selected based on their high performance in previous phi meter designs [23].

Excess oxygen is introduced to the extracted gas sample at the inlet of the phi meter via an inner tube within the quartz tubing. The addition of oxygen to the incoming gas mixture, combined with the presence of a high-temperature combustion catalyst, allows for lean combustion with a reactor exhaust exclusively comprised of $\mathrm{O}_{2}, \mathrm{CO}_{2}, \mathrm{H}_{2} \mathrm{O}, \mathrm{N}_{2}$, and Ar. Upon exiting the reactor, the exhaust flow is fed through a high-temperature mass flow controller (Alicat MCRW-5SLPM-D-HT/5M). The global equivalence ratio, $\phi_{\mathrm{G}}$, can be calculated by the phi meter's $\mathrm{O}_{2}$ and $\mathrm{CO}_{2}$ volume fraction, $X_{\mathrm{O}_{2}, \mathrm{~A}}$ and $X_{\mathrm{CO}_{2}, \mathrm{~A}}$, and the mass flow meter volumetric flow, $\dot{V}_{\mathrm{MFM}}$, measurements in the equation below, where $X_{\mathrm{O}_{2} \text {, Ent }}$ is the volume fraction of oxygen in the air (approx. 20.95\%) and $\dot{V}_{\mathrm{O}_{2} \text {,Ex }}$ is the volumetric flows of the excess oxygen, respectively.

$$
\phi_{\mathrm{G}}=1+\left(\frac{1-X_{\mathrm{O}_{2}, \mathrm{Ent}}}{X_{\mathrm{O}_{2}, \mathrm{Ent}}\left(1-X_{\mathrm{O}_{2}, \mathrm{~A}}-X_{\mathrm{CO}_{2}, \mathrm{~A}}\right)}\right)\left(\frac{\dot{V}_{\mathrm{O}_{2}, \mathrm{Ex}}}{\dot{V}_{\mathrm{MFM}}}-X_{\mathrm{O}_{2}, \mathrm{~A}}\right)
$$

A full dry basis derivation of Eq. 10 is documented in Ref. [10].

Compared to the previous phi meter designs, the second-generation phi meter includes a high-temperature mass flow controller (HTMFC) that regulates the total mass flow moving through the reactor. The HTMFC is heated using a 24 VDC heating element maintained

${ }^{1}$ Certain commercial products are identified in this report to specify adequately the equipment used. Such identification does not imply a recommendation by the National Institute of Standards and Technology, nor does it imply that this equipment is the best available for the purpose. 
Front

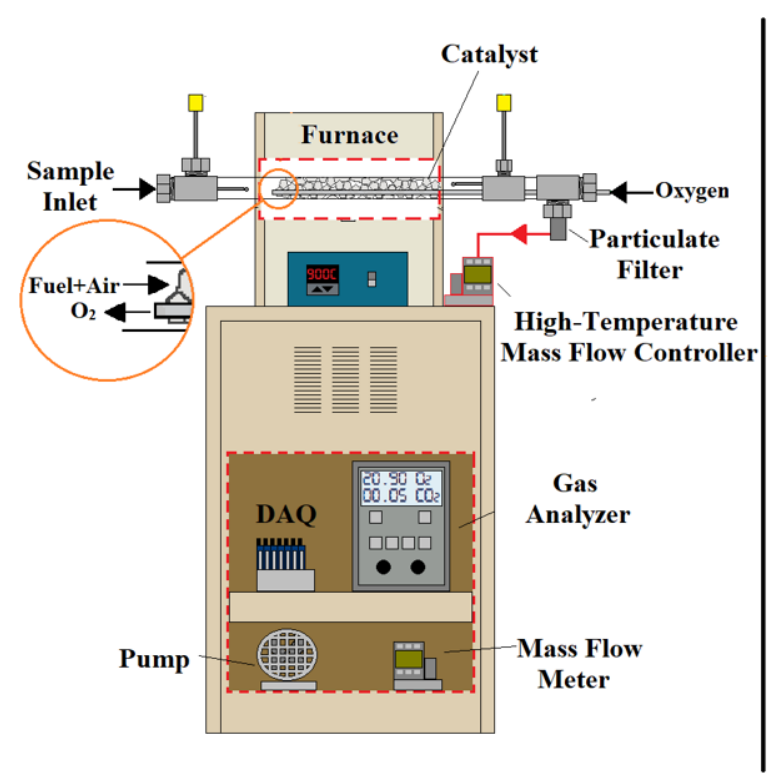

Rear

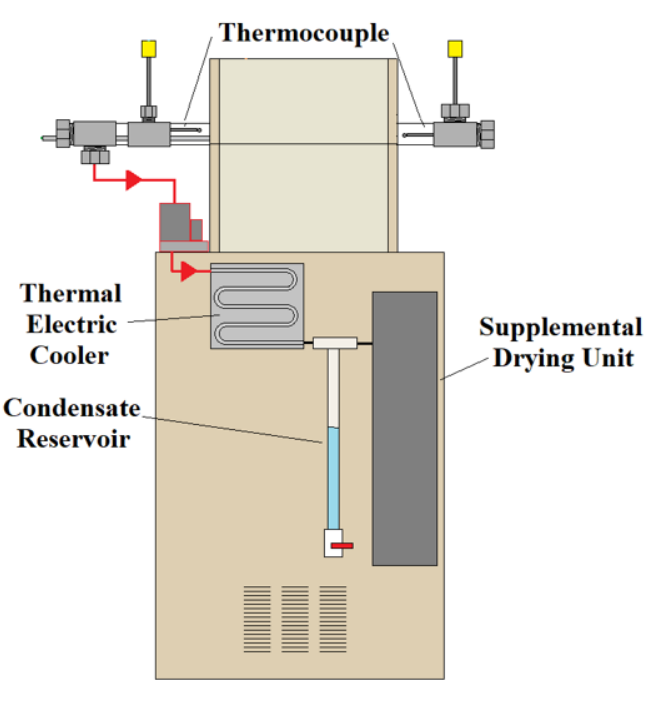

Fig. 1. Schematic of the second-generation phi meter.

at approximately $90{ }^{\circ} \mathrm{C}$. The elevated temperature of the HTMFC prevents water vapor in the reactor's exhaust from condensing, thus allowing the controller to account for the vapor mass in the sample line.

The utility of including the HTMFC is its ability to measure the total reactor exhaust flow, including water vapor. Assuming that the thermoelectric cooler, condensate reservoir, and supplemental drying unit are removing all water vapor from the reactor's exhaust, the portion of water vapor in the exhaust flow from the reactor, $\dot{V}_{\mathrm{H}_{2} \mathrm{O}}$, can be measured from the difference between the volumetric flow readings at the HTMFC, $\dot{V}_{\text {HTMFC }}$, and mass flow meter, $\dot{V}_{\text {MFM. }}$

$$
\dot{V}_{\mathrm{H}_{2} \mathrm{O}}=\dot{V}_{\mathrm{HTMFC}}-\dot{V}_{\mathrm{MFM}}
$$

In instances where stoichiometric ratios of combusted fuels are preserved, the accuracy of the experimental design can be verified using the carbon to hydrogen ratio. The carbon to hydrogen ratio is calculated from the $\mathrm{CO}_{2}$ and $\mathrm{H}_{2} \mathrm{O}$ volume fractions, $X_{\mathrm{CO}_{2}}$ and $X_{\mathrm{H}_{2} \mathrm{O}}$, determined at the HTMFC. This calculation is represented in Eq. 12, shown below:

$$
\frac{\mathrm{C}}{\mathrm{H}}=\frac{\mathrm{W}_{\mathrm{C}}}{\mathrm{W}_{\mathrm{H}}} \frac{\mathrm{x} X_{\mathrm{CO}_{2}}}{\mathrm{y} X_{\mathrm{H}_{2} \mathrm{O}}}
$$

Here $x$ and $y$ are the number of carbon and hydrogen atoms in $\mathrm{CO}_{2}$ and $\mathrm{H}_{2} \mathrm{O}$, respectively. The molecular weights of carbon and hydrogen are represented as $\mathrm{W}_{\mathrm{C}}$ and $\mathrm{W}_{\mathrm{H}}$.

During operation, the furnace temperature was maintained at $900{ }^{\circ} \mathrm{C} \pm 10{ }^{\circ} \mathrm{C}$ while the HTMFC and excess oxygen flow were set to 2.0 SLPM and 1.2 SLPM, respectively. These 
conditions were determined in a qualitative study that examined the phi meter's ability to combust high concentrations of soot at varying temperatures and residence times. Using a soot generator, a smoke plume with a soot concentration of $80 \mathrm{mg} / \mathrm{m}^{3} \pm 5 \mathrm{mg} / \mathrm{m}^{3}$ was directly fed into a constructed second-generation phi meter for $1 \mathrm{~min}$. Initially, a particulate filter was placed at the inlet of the phi meter to establish a baseline for comparison. The experiment was then repeated with a new particulate filter positioned at the furnace outlet with the same concentration of soot feeding into the phi meter while the furnace temperature and residence were held constant. Furnace temperatures varied between 800 and $900{ }^{\circ} \mathrm{C}$. Residence times were controlled by modifying the HTMFC and excess oxygen flows, which ranged from 1.0 SLPM and 2.0 SLPM for the HTMFC flow and 0.4 SLPM and 1.2 SLPM for the excess oxygen flow. The uncertainty of the HTMFC and oxygen flow was observed to be $2.0 \%$ of the flow setting.

Figure 2 provides a comparison between the soot filter placed at the inlet of the phi meter and the downstream soot filters, all which were obtained at a constant furnace temperature and residence times. The soot deposition on the downstream filter decreases as the residence time and furnace temperature increases. The lowest soot deposition was observed when the HTMFC and excess oxygen flows were set to 1 SLPM and 0.4 SLPM, respectively, at a furnace temperature of $900{ }^{\circ} \mathrm{C} \pm 10^{\circ} \mathrm{C}$. Although the higher residence time was observed to reduce soot in the exhaust via combustion, the higher flow conditions were selected to ensure a gas sample that would provide a significant measurement in downstream gas an analyzers. For all measurements reported here, the particulate filter positioned downstream from the reactor was periodically monitored. No soot deposition was observed, suggesting adequate operating conditions.

\section{Experimental Setup}

The second-generation phi meter was implemented in two series of experiments. A benchscale experimental series was initially conducted to demonstrate the second-generation phi meters design capabilities in a controlled environment. After the bench-scale experiments, two second-generation phi meters were constructed and implemented in a series of backdraft experiments that utilized a $2 / 5^{\text {th }}$ scale compartment.

\subsection{Bench-scale Experiments}

The second-generation phi meter was subjected to predetermined fuel-air ratios spanning from fuel-rich to fuel-lean. The experimental setup for the bench-scale experiments is shown in Fig. 3. Incoming gas mixtures comprised of fuel and air were controlled via the phi meter inlet flow. The inlet to the phi meter was partitioned such that fuel flow was maintained by an external mass flow controller mixed with ambient air that was then sampled into the phi meter. The incoming airflow was measured by an additional mass flow meter. The fuel-air ratio of the incoming mixture was determined from controlled fuel flow and measured airflow. Incoming airflow was determined by the difference between 


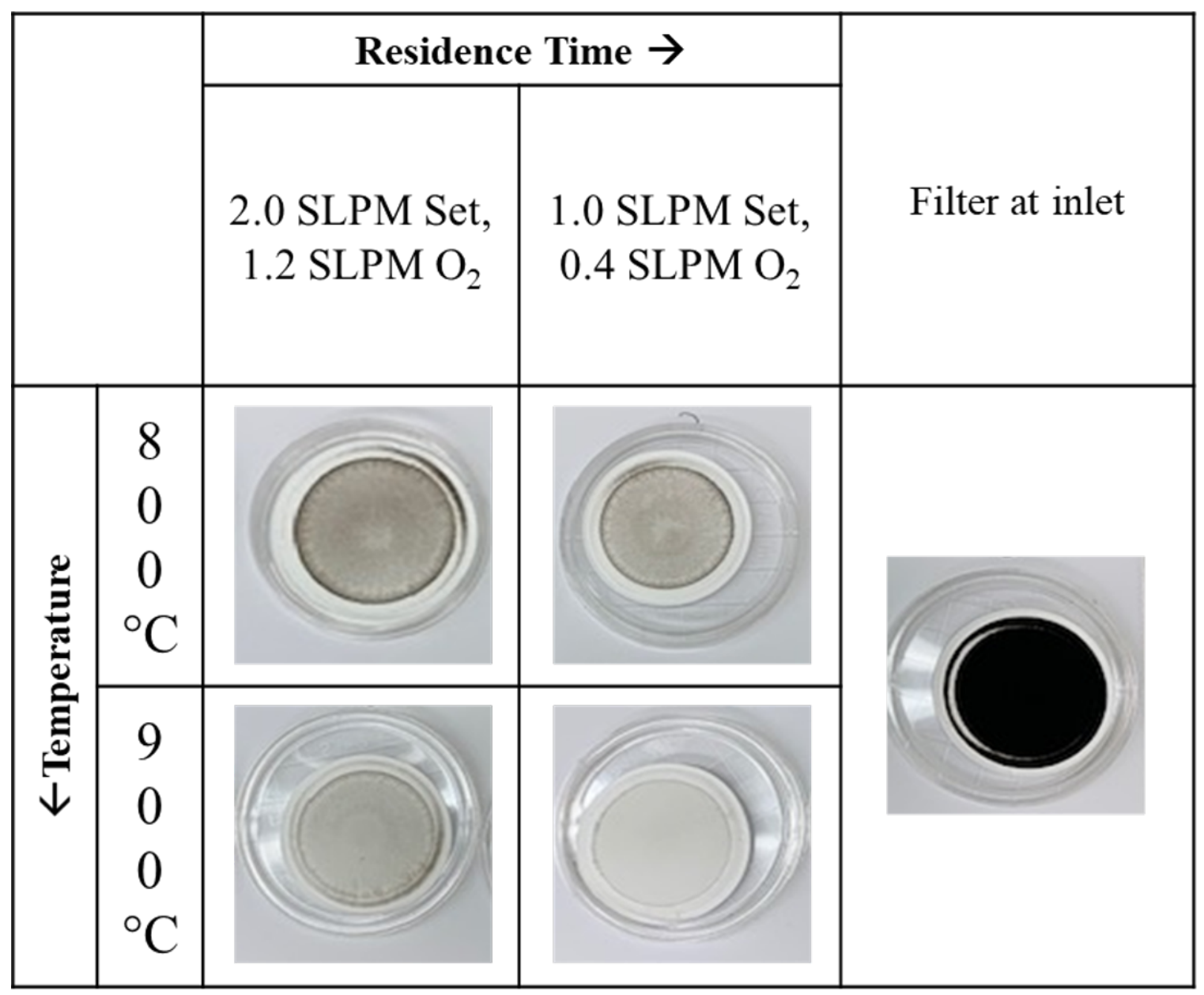

Fig. 2. Comparison of $47 \mathrm{~mm}$ soot filters positioned at the exhaust (left) and inlet (right) of the phi meter's reactor subjected to a gas stream with a soot concentration of $80 \mathrm{mg} / \mathrm{m}^{3} \pm 5 \mathrm{mg} / \mathrm{m}^{3}$ for approximately $1 \mathrm{~min}$.

the total mass flow set by the high-temperature mass flow controller and the mass flow of the fuel. Methane, propane, and propene were selected as the fuels of interest.

A mass balance evaluation was applied to provide a more in-depth verification method. The total mass flow present at the inlet of the phi meter, $\dot{m}_{\mathrm{in}}$, which includes the mass of incoming fuel, $\dot{m}_{\text {Fuel }}$, air, $\dot{m}_{\text {Air }}$ and excess oxygen, $\dot{m}_{\mathrm{O}_{2}, \text { Ex }}$, is compared to the total mass flow at the high-temperature mass flow controller, $\dot{m}_{\mathrm{HTMFC}}$, comprised of the mass of remaining oxygen, $\dot{m}_{\mathrm{O}_{2}, \mathrm{HTMFC}}$, carbon dioxide, $\dot{m}_{\mathrm{CO}_{2}, \mathrm{HTMFC}}$, water vapor, $\dot{m}_{\mathrm{H}_{2} \mathrm{O}, \mathrm{HTMFC}}$,

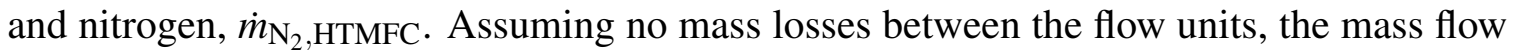
of nitrogen is determined from the difference between the total mass flow measured at the mass flow meter, $\dot{m}_{\mathrm{MFM}}$, and the mass flow of $\mathrm{O}_{2}$ and $\mathrm{CO}_{2}$. The mass flow of $\mathrm{O}_{2}$ and $\mathrm{CO}_{2}$ is calculated from the gas analyzer $\mathrm{O}_{2}$ and $\mathrm{CO}_{2}$ mass fraction measurements, $Y_{\mathrm{O}_{2}}$ and $Y_{\mathrm{CO}_{2}}$, and the total mass flow meter reading. 


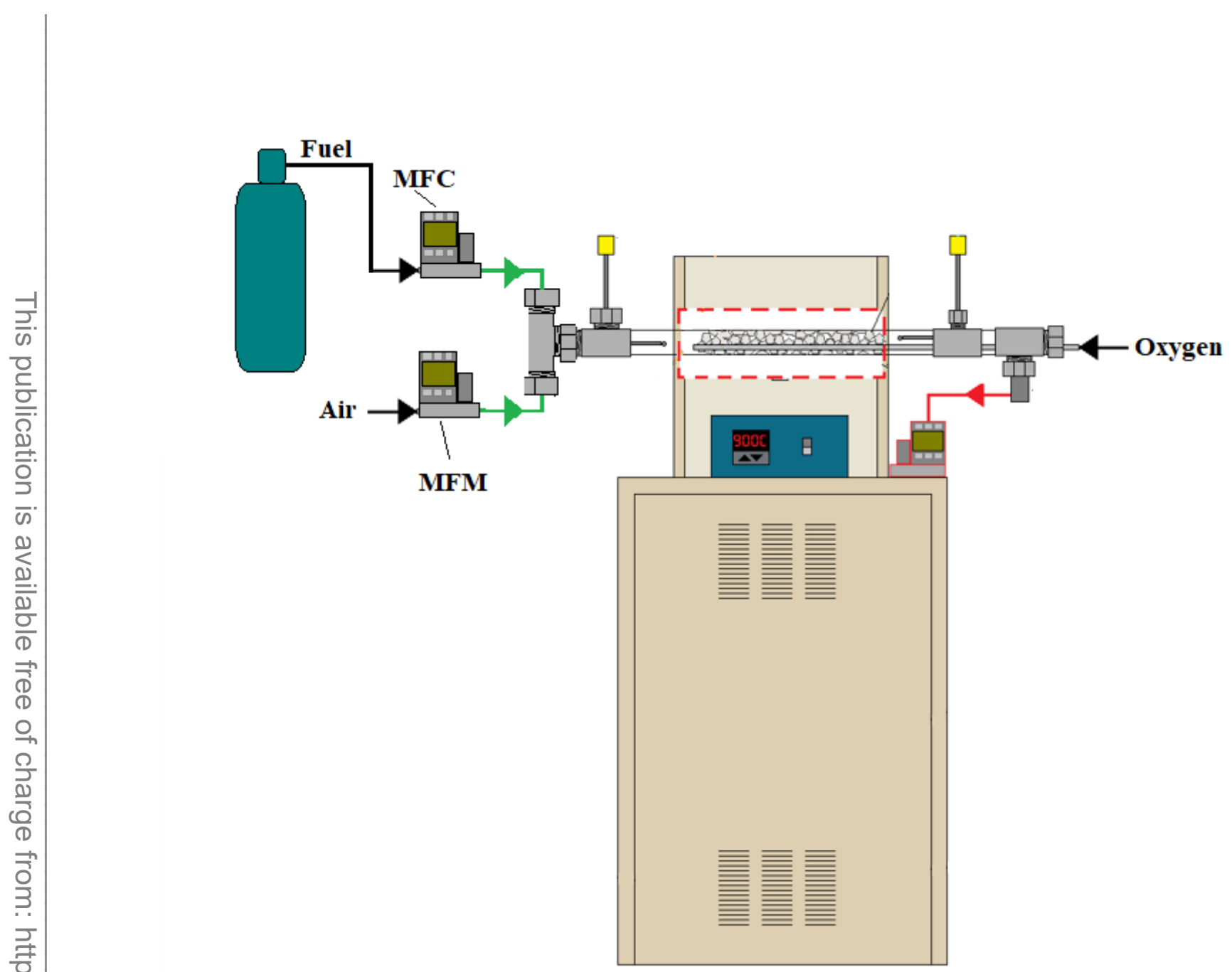

Fig. 3. Experimental setup for bench-scale experiments

$$
\begin{gathered}
\dot{m}_{\mathrm{in}}=\dot{m}_{\mathrm{HTMFC}} \\
\dot{m}_{\text {Fuel }}+\dot{m}_{\mathrm{Air}}+\dot{m}_{\mathrm{O}_{2}, \mathrm{Ex}}=\dot{m}_{\mathrm{O}_{2}, \mathrm{HTMFC}}+\dot{m}_{\mathrm{CO}_{2}, \mathrm{HTMFC}}+\dot{m}_{\mathrm{H}_{2} \mathrm{O}, \mathrm{HTMFC}}+\dot{m}_{\mathrm{N}_{2}, \mathrm{HTMFC}}
\end{gathered}
$$

where

$$
\dot{m}_{\mathrm{N}_{2}, \mathrm{HTMFC}}=\dot{m}_{\mathrm{MFM}}-\dot{m}_{\mathrm{O}_{2}, \mathrm{HTMFC}}-\dot{m}_{\mathrm{CO}_{2}, \mathrm{HTMFC}}
$$

All measurements were collected and monitored by a data acquisition system (DAQ). Data samples were recorded at $1 \mathrm{~Hz}$ for 1 minute. All experimental conditions were repeated at least twice. An extensive uncertainty analysis of all phi meter measurements is provided in Appendix $\mathrm{B}^{2}$. The uncertainty of time-averaged measurements is estimated using the law of propagation of uncertainty which combines the Type A and B evaluation of standard uncertainty. The Type B evaluation of uncertainty is the dominant error for most time-averaged measurements acquired in the bench-top experiments.

${ }^{2}$ Unless otherwise stated, the uncertainty of the measurements reported in this work are expressed with a coverage factor of 2 , assuming a $95 \%$ confidence level. 


\subsection{Backdraft Experiments}

Backdraft experiments incorporated a $2 / 5^{\text {th }}$ scale compartment capable of various configurations (i.e., doorway size, igniter location, spark delay time). Backdraft experiments were initiated when a small box burner, fed fuel via mass flow controller, was ignited using a propane wand. Backdraft gas species measurements reported here were obtained from a controlled methane fire size of $25.0 \mathrm{~kW} \pm 1.0 \mathrm{~kW}$ using the box burner. Initially, the fire burned while the compartment doorway remained open for $60 \mathrm{~s}$. After the front doorway was closed, methane gas continued to be fed to the box burner until a predetermined fueloff time was achieved. The doorway remained closed $30 \mathrm{~s}$ after the predetermined fuel-off time, upon which after the doorway opened and a potential backdraft could occur. An extensive description of the backdraft experiments is provided in Ref. [24].

During the backdraft experiment, gas samples were collected in the upper and middle layers of the compartment, which were approximately $0.9 \mathrm{~m} \pm 0.05 \mathrm{~m}$ and $0.5 \mathrm{~m} \pm 0.05 \mathrm{~m}$ from the compartment floor, respectively. Extracted gas samples were portioned into a phi meter, gas analyzer, and grab sample container at both locations. A schematic of the experimental setup in regards to gas extraction is shown in Figure 4. The gas analyzer included two non-dispersive infrared sensors and a paramagnetic sensor to provide real-time $\mathrm{CO}_{2}$, $\mathrm{CO}$, and $\mathrm{O}_{2}$ concentration measurements, respectively. The grab sample container was used to collect well-mixed gas samples that would be analyzed via a gas chromatograph/mass spectrometer (GC/MS) system to estimate time-averaged gas species concentrations [9]. Grab samples were extracted for a $1 \mathrm{~min}$ period $70 \mathrm{sec}$ prior to the door opening. To preserve the gas analyzer's integrity, a chiller was positioned upstream of its inlet, indicating that all gas species concentration measurements are obtained on a dry basis. Sample lines feeding into the phi meter and grab sample container were heated (approx. $90{ }^{\circ} \mathrm{C} \pm 5{ }^{\circ} \mathrm{C}$ ) using heating tape for measurements to account for water vapor in the extracted sample.

The gas species concentration measurements obtained from the gas analyzer and GC/MS analysis were used to verify the equivalence ratio measurements made in the phi meter. For gas analyzer and GC/MS measurements, the global equivalence ratio was calculated from the equation below:

$$
\phi_{\mathrm{G}}=\frac{\left[\sum X_{\left(\mathrm{C}_{\mathrm{x}} \mathrm{H}_{\mathrm{y}} \mathrm{O}_{\mathrm{z}}\right)} \cdot\left(\mathrm{x}+\frac{\mathrm{y}}{4}-\frac{\mathrm{z}}{2}\right)\right]+0.5 X_{\mathrm{CO}}+X_{\mathrm{CO}_{2}}}{X_{\mathrm{O}_{2}}+X_{\mathrm{CO}_{2}}+0.5 X_{\mathrm{CO}}+0.5 X_{\mathrm{H}_{2} \mathrm{O}}}
$$

In equivalence ratio calculations determined via GC/MS measurements, the concentration of fuel is a collective sum of the parent fuel and other hydrocarbons (e.g., hydrogen, ethane, ethylene, acetylene, benzene), if detected. For equivalence ratio calculation made from the gas analyzer, fuel was exclusively assumed to be the parent fuel and was estimated from measurements via stoichiometric ratios.

Local equivalence ratios were calculated from a combination of phi meter and gas analyzer $\mathrm{O}_{2}$ measurements. The gas analyzer provided additional oxygen concentration measurements at the inlet of the phi meter which allows for the local equivalence ratio to be 


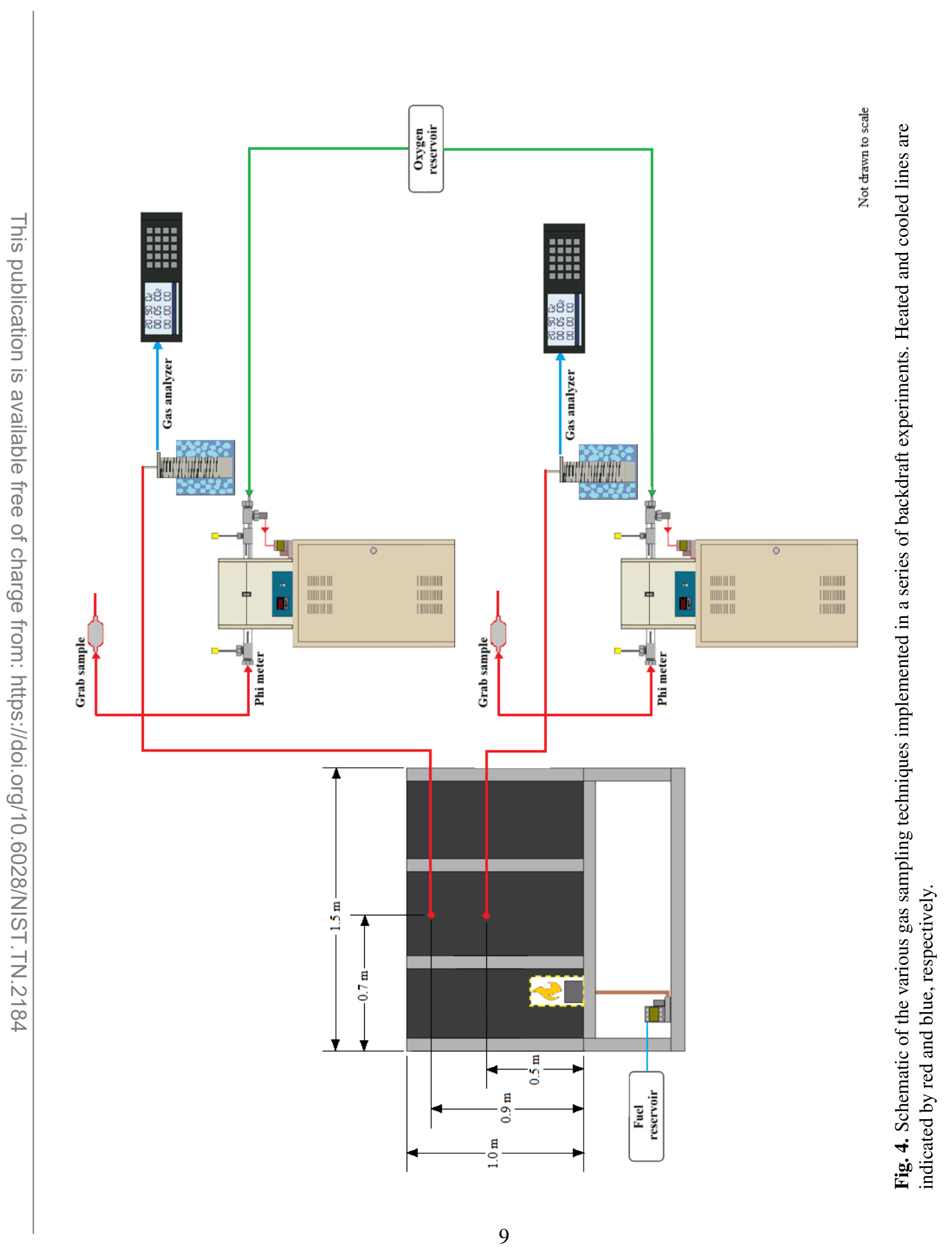


calculated using the equation below:

$$
\phi_{\mathrm{L}}=1+\left(\frac{X_{\mathrm{N}_{2}, \text { In }}}{X_{\mathrm{O}_{2}, \text { In }}}\right)\left(\frac{\dot{V}_{\mathrm{ex}}}{\dot{V}_{\mathrm{N}_{2}, \mathrm{MFM}}}-\frac{X_{\mathrm{O}_{2}, \mathrm{~A}}}{X_{\mathrm{N}_{2}, \mathrm{~A}}}\right)
$$

Here, $X_{\mathrm{O}_{2} \text {,In }}$ and $X_{\mathrm{N}_{2} \text {,In }}$ represent the $\mathrm{O}_{2}$ and $\mathrm{N}_{2}$ concentrations measurements in gas sample at the inlet of the phi-meter's, respectively, estimated from the gas analyzer. The concentration and volumetric flow rate of $\mathrm{N}_{2}$ in the phi meter's reactor dried exhaust, $X_{\mathrm{N}_{2}, \mathrm{~A}}$ and $\dot{V}_{\mathrm{N}_{2}, \text { MFM }}$ were estimated from Eq. 15. A full derivation of Eq. 17 is provided in Appendix C.

Using gas species measurements made by the gas analyzer and GC/MS analysis, the local equivalence ratio was calculated using Eq. 18.

$$
\phi_{\mathrm{L}}=\frac{\sum X_{\left(\mathrm{C}_{\mathrm{x}} \mathrm{H}_{\mathrm{y}} \mathrm{O}_{\mathrm{z}}\right)} \cdot\left(\mathrm{x}+\frac{\mathrm{y}}{4}-\frac{\mathrm{z}}{2}\right)}{X_{\mathrm{O}_{2}}}
$$

Phi meter and gas analyzer data samples were recorded at $1 \mathrm{~Hz}$ throughout the experiment using separate DAQ. Grab samples were extracted for a 1 min period before the doorway opening. The real-time measurements' uncertainty was estimated from the Type B evaluation of uncertainty defined by the instrumentation error. Time-averaged measurement uncertainties were estimated using the law of propagation of uncertainty which combines the Type A and B evaluation of uncertainty. A full description of the uncertainty in the measurements made by the phi meter and additional instruments used for gas analysis is provided in Appendix B and D. 


\section{Results and Discussion}

This section presents the global and local equivalence ratio measurements obtained in the bench-scale and the $2 / 5^{\text {th }}$ scale compartment experiments. Water vapor measurements are provided from the bench-scale experiments. Verification from independent measurement schemes are provided in both series of experiments.

\subsection{Bench-scale Experiments}

Figure 5 shows the comparison between global equivalence ratio measurements determined from Eq. 10 and the predetermined fuel-air mixtures at the inlet. The dotted line represents the equivalency between the calculated and measured values. Since the composition of the sampled flow is consistent, the local and global equivalence ratios are equivalent. The measured time-averaged $\bar{\phi}_{\mathrm{G}}$ for all fuel and fuel-air ratios are shown to agree with the monitored incoming gas mixtures. The consistency between the phi meter measurements and the estimated incoming equivalence ratio suggests that the incoming fuel completely combusts within the reactor under the given configuration (i.e., high-temperature mass flow controller and furnace temperature settings). The indication that all incoming fuel is combusted within the phi meter permits the calculation of water vapor flow from half the product of the number of hydrogen atoms in the incoming fuel, $y$, and the volumetric flow of the fuel, $\dot{V}_{\text {Fuel }}$, as represented below:

$$
\dot{V}_{\mathrm{H}_{2} \mathrm{O}, \mathrm{HTMFC}}=\frac{y}{2} \dot{V}_{\text {Fuel }}
$$

The comparison between the measured time-averaged water vapor flow, $\overline{\mathrm{V}}_{\mathrm{H}_{2} \mathrm{O}, \mathrm{HTMFC}}$, and predicted value calculated from Eq. 11 and 19, respectively, is presented in Fig 6. The water vapor flow measurements determined from the flow readings are observed to match the calculated water vapor flows within the experimental uncertainty, indicated by the dotted line where the calculated and measured values are equivalent. In propane cases, a discrepancy between the calculated and measured flow appears to increase when water vapor concentration is greater than $15 \%$ of the reactor's exhaust. The deviation between the calculated and measured water vapor flows at high concentrations may attribute to the inadequate performance of the thermoelectric cooler or supplemental drying unit. An increase in the flow's residence time in the thermoelectric cooler and supplemental dryer or a decrease in the thermoelectric coolers operating temperature may reduce the discrepancy between the measured and calculated values.

The estimated carbon to hydrogen ratio from the parent fuel, indicated by the dotted line, and the calculated time-averaged carbon to hydrogen ratio, $\overline{\mathrm{C} / \mathrm{H}}$, determined from the $\mathrm{CO}_{2}$ and $\mathrm{H}_{2} \mathrm{O}$ measurements are plotted as a function of the measured time-averaged $\bar{\phi}_{\mathrm{G}}$ and shown in Fig. 7. For all measurements, the experimental uncertainty of the calculated $\overline{\mathrm{C} / \mathrm{H}}$ is within parent fuels' carbon to hydrogen ratio. In several instances, the theoretical and calculated values are nearly matching, verifying the accuracy of the $\mathrm{CO}_{2}$ and $\mathrm{H}_{2} \mathrm{O}$ concentration measurements. The agreement between the theoretical and measured carbon to 


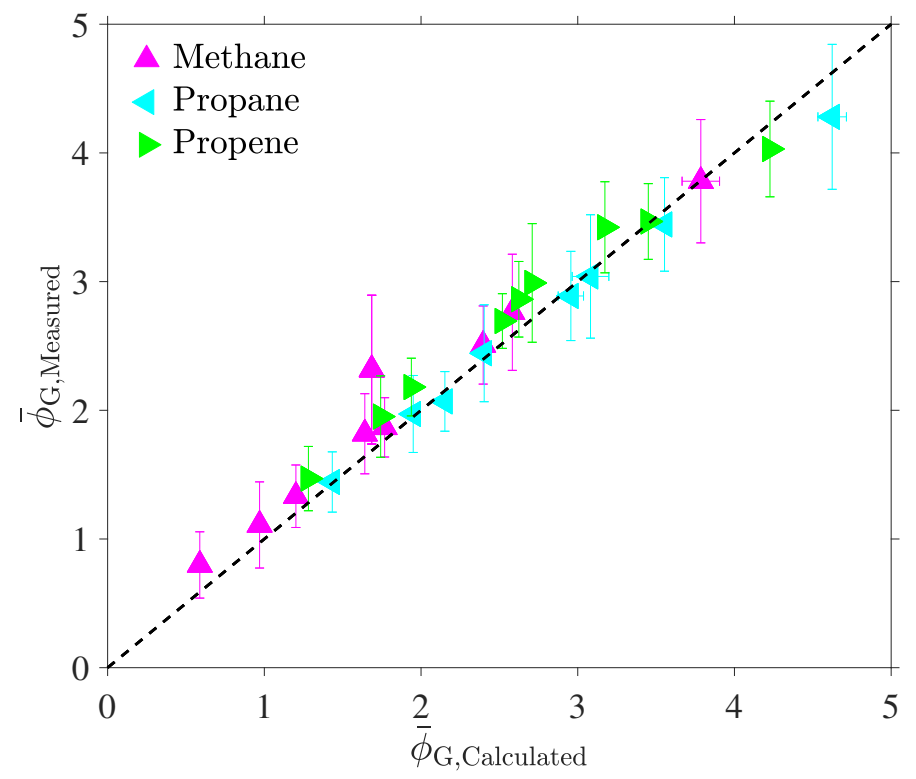

Fig. 5. Time-averaged global equivalence ratio measurements determined via Eq. 10 as a function of the global equivalence ratio estimated from predetermined fuel-air mixtures. The dotted line represents the equivalency between the calculated and measured values. The uncertainty of the time-averaged global equivalence ratio is estimated from the combined Type A and B evaluation of standard uncertainty. A full description of the measurements' uncertainty is provided in Appendix B.1.

hydrogen ratio demonstrates the enhanced phi meter's potential for investigating combustion processes by measuring the $\mathrm{C} / \mathrm{H}$ ratio without any knowledge of the parent fuel.

Figure 8 shows the ratio between the time-averaged total mass flow calculated at the high-temperature mass flow controller, $\overline{\dot{m}}_{\text {HTMFC }}$, and measured time-averaged mass flow rate at the inlet of the phi meter, $\overline{\dot{m}}_{\mathrm{in}}$, as a function of the measured time-averaged global equivalence ratio, $\bar{\phi}_{\mathrm{G}}$. The dotted line represents unity. For each measurement, unity falls within the experimental uncertainty of each mass ratio. In some cases, the calculated mass ratios are near unity, which indicates minimal mass loss within the sample line. The agreement between masses for varying equivalence ratios and fuels further supports the validity of the $\mathrm{O}_{2}, \mathrm{CO}_{2}, \mathrm{H}_{2} \mathrm{O}$, and $\mathrm{N}_{2}$ concentration measurements and the design of the phi meter. 


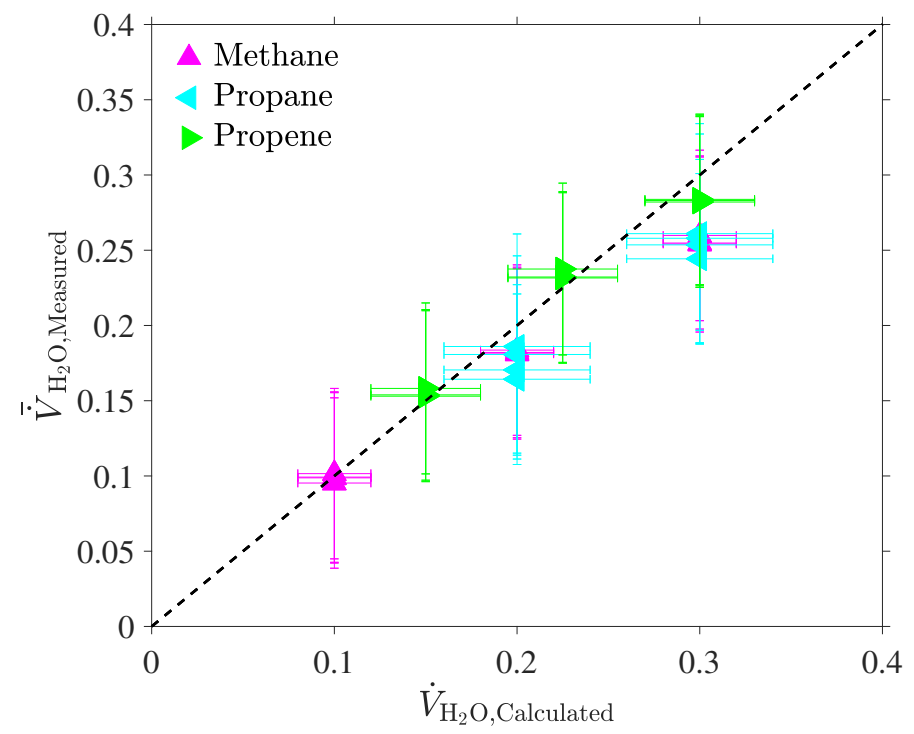

Fig. 6. Time-averaged volumetric flow of water vapor via Eq. 11 as a function of the anticipated volumetric flow of water vapor estimated from Eq. 19. The dotted line represents the equivalency between the calculated and measured values. The uncertainty of the time-averaged water vapor flows, both measured and calculated, are estimated from the combined Type A and B evaluation of standard uncertainty. A full description of the measurements' uncertainty is provided in Appendix B.2. 


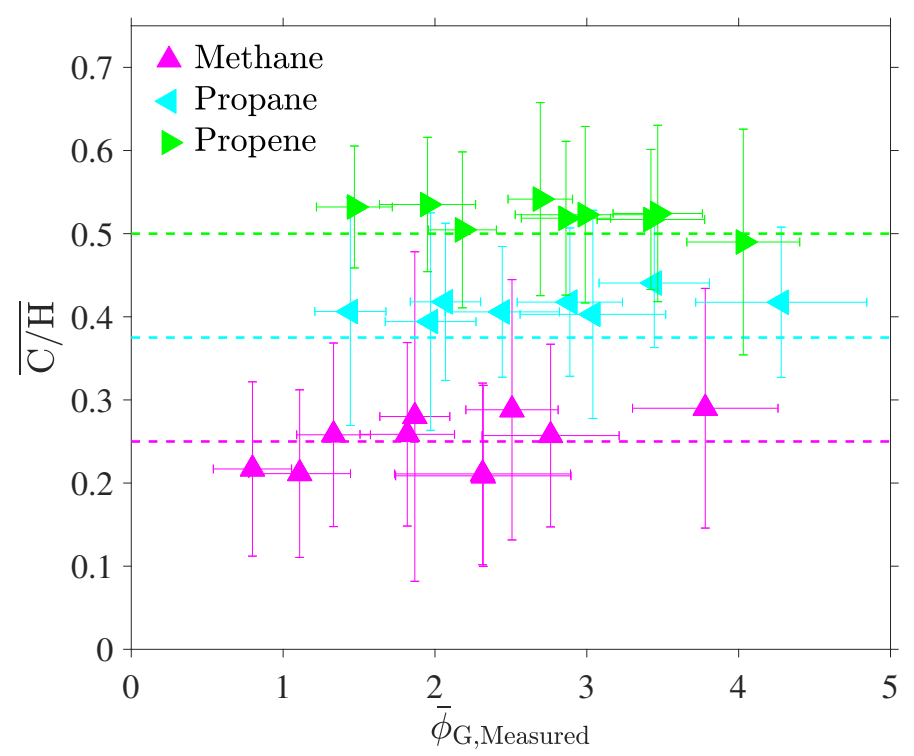

Fig. 7. Time-averaged carbon to hydrogen ratio calculated from the $\mathrm{CO}_{2}$ and $\mathrm{H}_{2} \mathrm{O}$ species measurements compared to the theoretical values (dotted lines) as a function of the measured global equivalence ratio. The uncertainty of the time-averaged carbon to hydrogen and global equivalence ratios are estimated from the combined Type A and B evaluation of standard uncertainty. A full description of the carbon to hydrogen and global equivalence ratio measurements' uncertainty are provided in Appendix B.3 and B.1, respectively. 


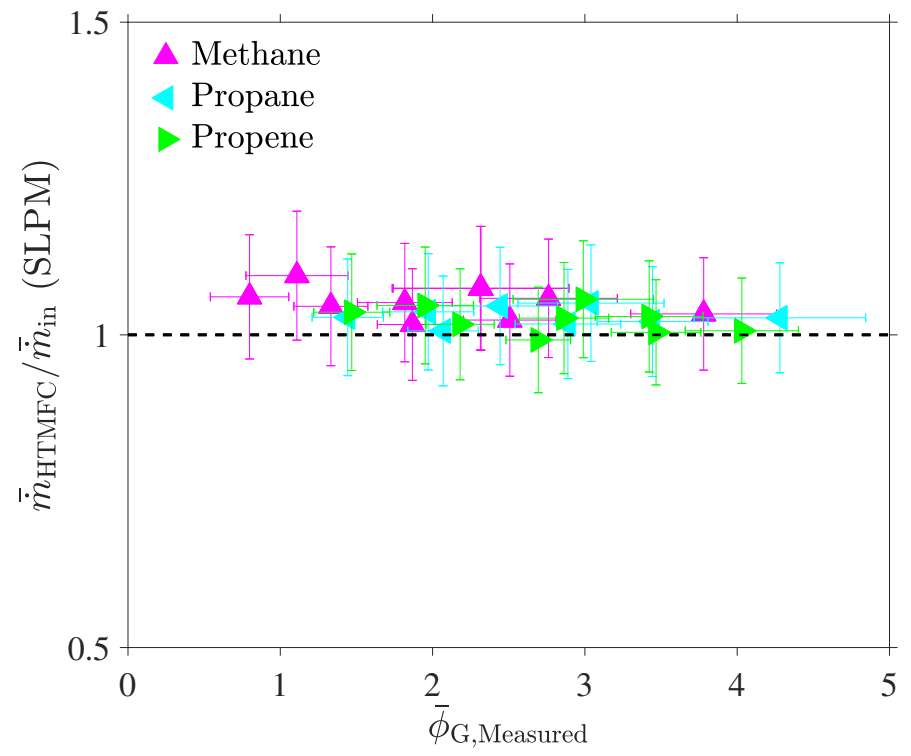

Fig. 8. The time-averaged ratio of the mass flow rate at the high temperature mass flow controller to the inlet of the phi meter calculated via Eqs.13-15 as a function of the measured global equivalence ratio. The dotted line represents the equivalency between the calculated and measured values. The uncertainty of the time-averaged mass and global equivalence ratios are estimated from the combined Type A and B evaluation of standard uncertainty. A full description of the mass and global equivalence ratio measurements' uncertainty are provided in Appendix B.4 and B.1, respectively. 


\subsection{Backdraft Experiments}

Figures 9 and 10 show the real-time global and local equivalence ratio measurements, respectively, obtained from the phi meters and gas analyzers at approximately $0.5 \mathrm{~m}$ and $0.9 \mathrm{~m}$ from the compartment floor during a backdraft experiment. In this experiment, a $25.0 \mathrm{~kW}$ methane fire burned in the $2 / 5^{\text {th }}$ scale compartment for $360 \mathrm{sec}$, of which the compartment door was opened for the initial $60 \mathrm{sec}$. The sparker was positioned $51 \mathrm{~cm} \pm 1 \mathrm{~cm}$ from the compartment floor (mid-spark position) and set to a 0 -sec spark delay from when the doorway opened at $390 \mathrm{sec}$. A backdraft event was observed upon opening the doorway $30 \mathrm{~s}$ after the fuel flow was shut off at $360 \mathrm{sec}$.
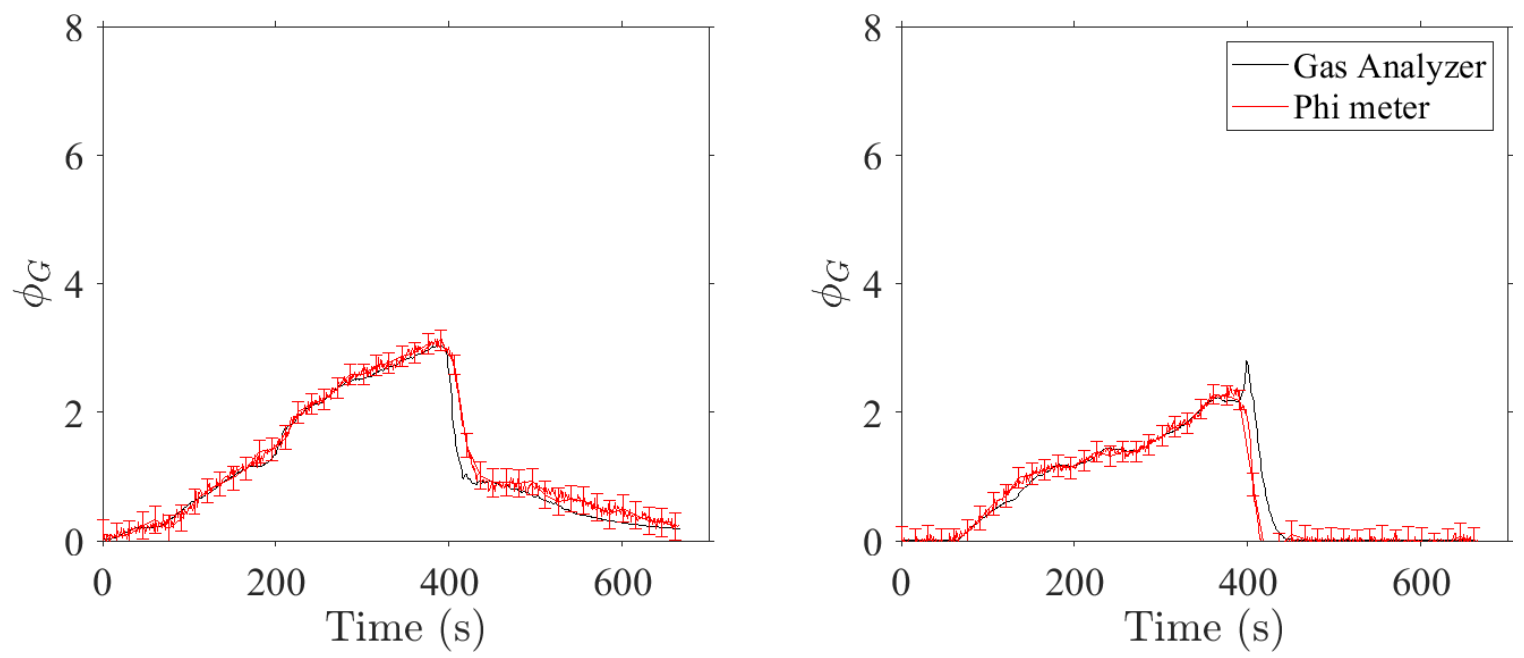

Fig. 9. Real-time global equivalence ratio measurements at approximately $0.9 \mathrm{~m}$ (left) and $0.5 \mathrm{~m}$ (right) from the compartment floor during a $25.0 \mathrm{~kW}$ methane fire with a fuel-off time of $360 \mathrm{sec}$ and a compartment configuration of a window opening, mid-spark position, 0 -sec spark delay from when the doorway opened at $390 \mathrm{sec}$ [24]. The uncertainty of the real-time global equivalence ratios measured is estimated via the law of propagation of uncertainty. A full description of the global equivalence ratio measurements' uncertainty is provided in Appendix B.1.

The global equivalence ratios measured in the upper and middle layers of the compartment follow a similar trend but are not equal, suggesting non-uniform gas mixture longitudinally within the compartment. When the compartment is closed and fuel continues to burn (à is constant), ventilation becomes increasingly limited $(\dot{\varepsilon}+\dot{\eta} \rightarrow 0)$ causing an increase in the global equivalence ratio. At approximately $390 \mathrm{sec}$, the global equivalence ratio rapidly decreases, corresponding to doorway opening and the ventalation within the compartment to increase. The global ratio estimations made from the gas analyzers are observed to agree with the phi meter measurements. The consensus between the two independent measurements validates the functionality of the second-generation phi meter in an applicable setting.

Similar to the global equivalence ratio measurements, the local equivalence ratio measurements obtained in the upper and middle layer of the compartment follow a similar 

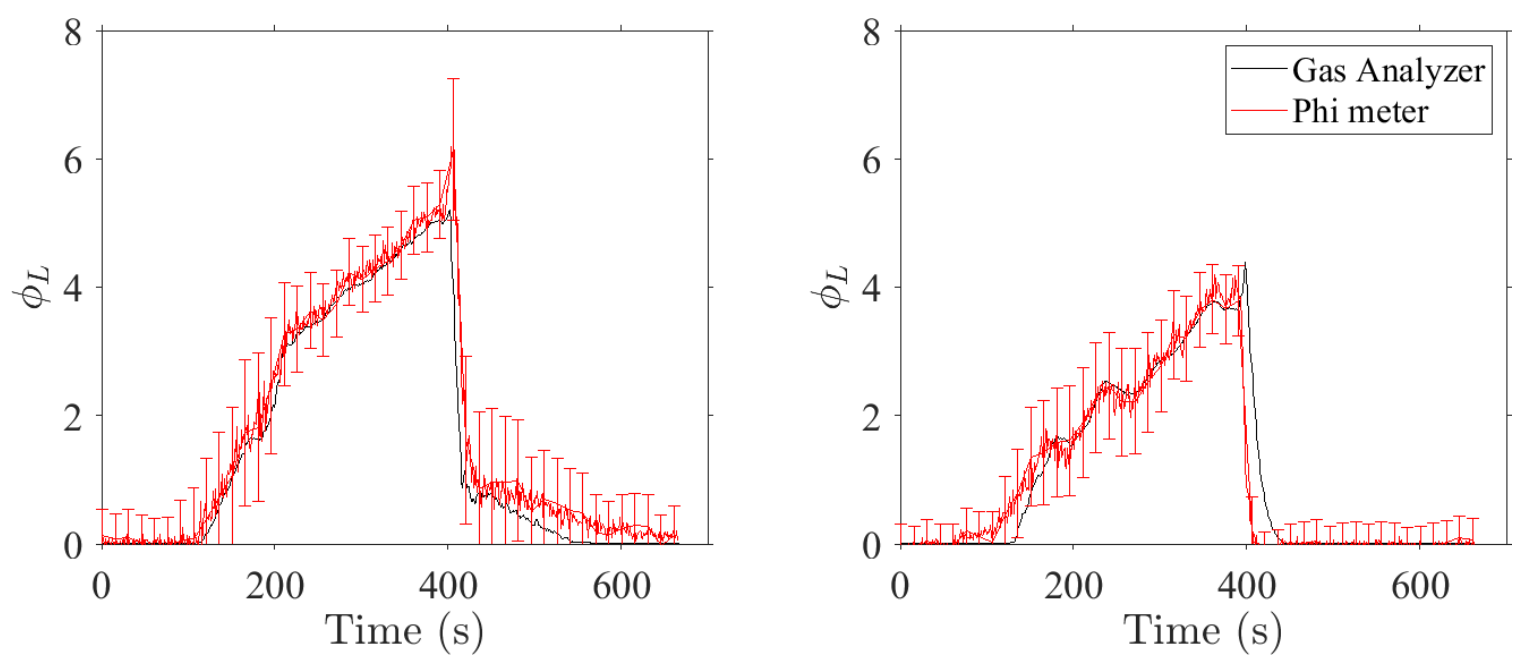

Fig. 10. Real-time local equivalence ratio measurements at approximately $0.9 \mathrm{~m}$ (left) and $0.5 \mathrm{~m}$ (right) from the compartment floor during a $25.0 \mathrm{~kW}$ methane fire with a fuel-off time of $360 \mathrm{sec}$ and a compartment configuration of a window opening, mid-spark position, 0 -sec spark delay from when the doorway opened at $390 \mathrm{sec}$ [24]. The uncertainty of the real-time local equivalence ratios measured is estimated via the law of propagation of uncertainty. A full description of the local equivalence ratio measurements' uncertainty is provided in Appendix B.5.

trend but are not equivalent. The real-time local equivalence ratio measurements in the upper layer are observed to be higher compared to the middle compartment section, indicating a richer unburned fuel concentration in the upper layer of the compartment. Local equivalence ratio measurements estimated from the gas analyzer validates the phi meter measurements since both data sets agree. In comparison to the real-time global equivalence ratio measurements, local equivalence ratio measurements are always higher beyond and and lower before stoichiometric conditions. From Eqs. 8 and 9, the global and local equivalence ratio measurements are equivalent at stoichiometric conditions which is shown in Figs. 9 and 10.

Figure 11 provides the real-time carbon to hydrogen ratios estimated in the upper and middle layer of the compartment. The estimations made from the phi meter are shown to gradually approach the carbon to hydrogen ratio of the parent fuel as more fuel is fed into the compartment. The discrepancy between the carbon to hydrogen ratio of the real-time phi meter estimations and the parent fuel suggests a heterogeneous gas mixture exist within the compartment which becomes more homogeneous over time.

The time-averaged global and local equivalence ratio measurements estimated from the phi meter were compared to their respective counterparts determined from the GC/MS analysis for all backdraft experiments. Figures 12 and 13 shows the global and local equivalence ratio measurements, respectively, taken at the upper and middle layers of the compartment for all backdraft experiments. The series of experiments varied by fuel-off time, which ranged from $360 \mathrm{~s}$ to $450 \mathrm{~s}$.

In Figs. 12 and 13, unity is represented by a dotted line. For most experiments, the phi 

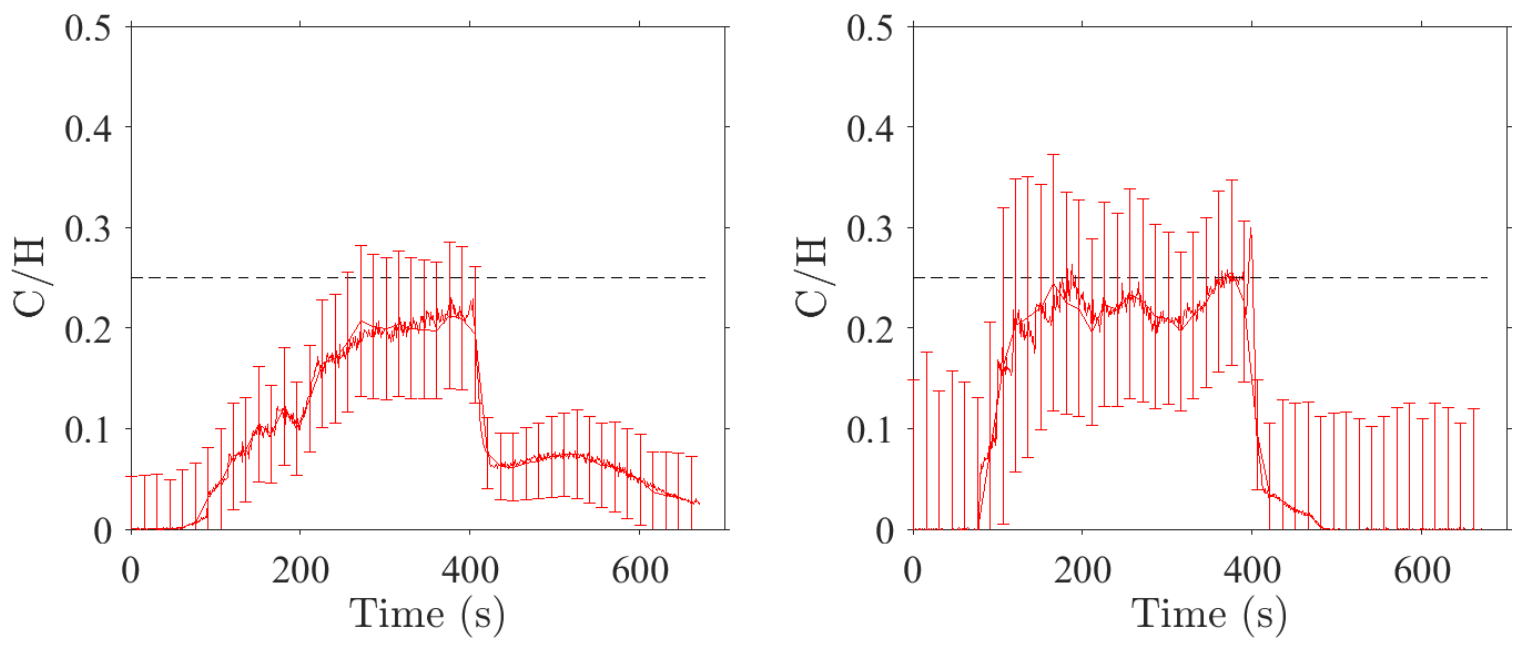

Fig. 11. Real-time carbon to hydrogen estimations at approximately $0.9 \mathrm{~m}$ (left) and $0.5 \mathrm{~m}$ (right) from the compartment floor during a $25.0 \mathrm{~kW}$ methane fire with a fuel-off time of $360 \mathrm{sec}$ and a compartment configuration of a window opening, mid-spark position, 0 -sec spark delay from when the doorway opened at $390 \mathrm{sec}$ [24]. The dotted line represents the parent fuel's theoretical carbon to hydrogen ratio of methane (0.25). The uncertainty of the real-time local equivalence ratios measured is estimated via the law of propagation of uncertainty. A full description of the measurements' uncertainty is provided in Appendix B.5.
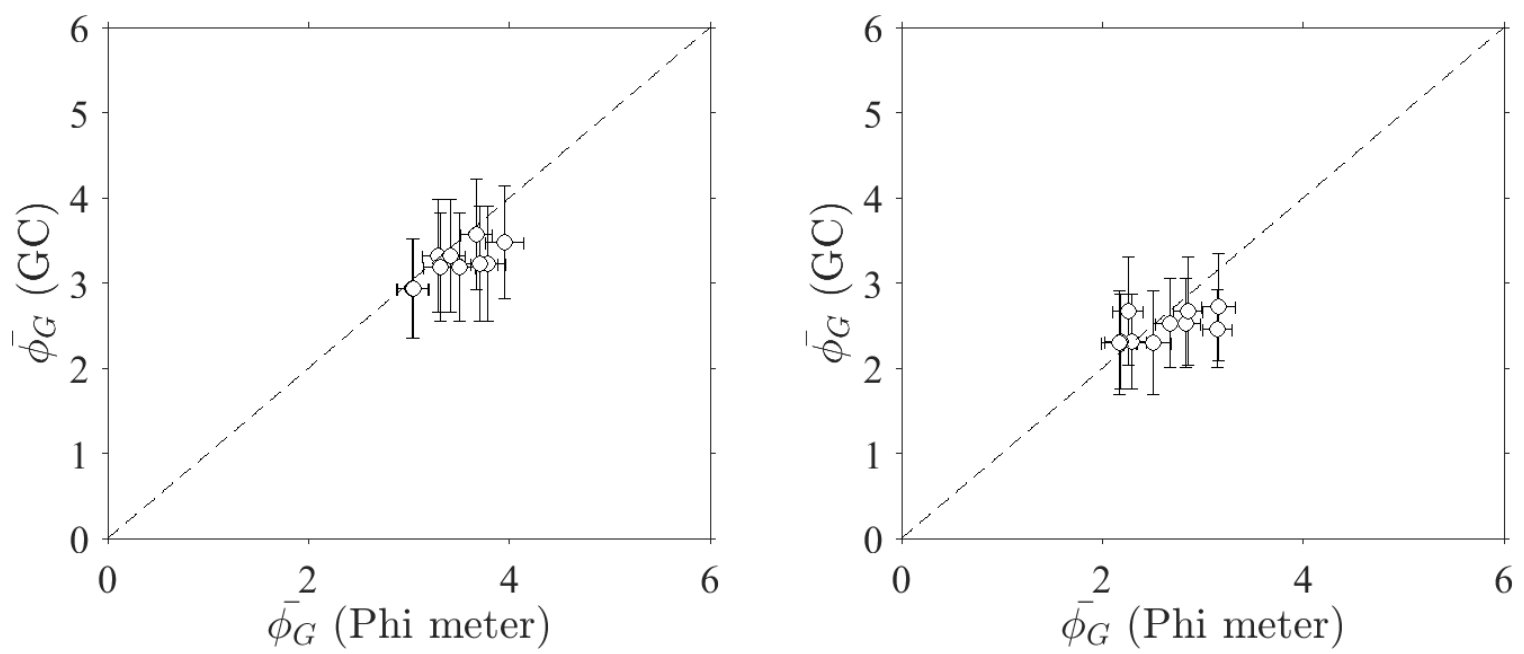

Fig. 12. Time-averaged global equivalence ratio measurements from the upper (left) and middle (right) section of the compartment for a series of $25.0 \mathrm{~kW}$ methane fires with fuel-off times ranging from 360 to $450 \mathrm{~s}$. The dotted line represents the equivalency between the phi meter and GC/MS values. A full description of the phi meter and GC/MS measurements' uncertainty are provided in Appendix B.1 and D, respectively.

meter and GC/MS time-averaged global and local equivalence ratios are equivalent within experimental uncertainty. As shown in Fig. 13, a small portion of the local equivalence 

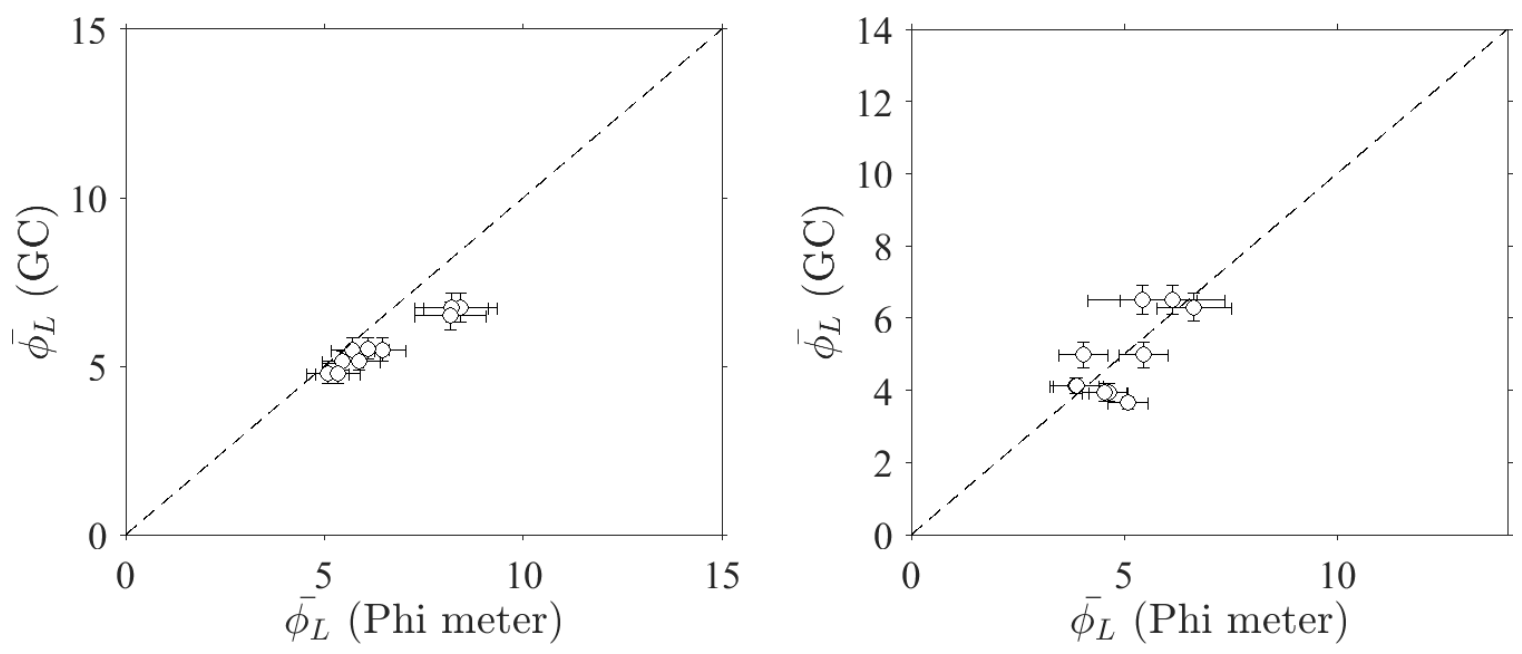

Fig. 13. Time-averaged local equivalence ratio measurements from the upper (left) and middle (right) section of the compartment for a series of $25.0 \mathrm{~kW}$ methane fires with fuel-off times ranging from 360 to $450 \mathrm{~s}$. The dotted line represents the equivalency between the phi meter and GC/MS values. A full description of the phi meter and GC/MS measurements' uncertainty are provided in Appendix B.5 and D, respectively.

ratio measurements are askew from unity, which is most likely attributed to an irregular grab sample used in the GC/MS analysis.

\section{Conclusion}

This report documents the capabilities of a second-generation phi meter. In summary, realtime and time-averaged global and local equivalence ratios, water vapor flows, and carbon to hydrogen ratios are measured in a series of bench-scale and $2 / 5^{\text {th }}$ scale compartment experiments. Measurements are verified through secondary measurement techniques, which are in fair agreement with the calculated values within experimental uncertainty. The enhanced phi meter's capability to measure the global and local equivalence ratio simultaneously with $\mathrm{O}_{2}, \mathrm{CO}_{2}$, and $\mathrm{H}_{2} \mathrm{O}$ has significant potential for investigating ventilation in combustion processes.

\section{Acknowledgments}

The authors would like to acknowledge Michael Selepak, who aided in the construction of the second-generation phi meter. 


\section{References}

[1] Stavropoulos P, Michalakou A, Skevis G, Couris S (2005) Quantitative local equivalence ratio determination in laminar premixed methane-air flames by laser induced breakdown spectroscopy (LIBS). Chemical Physics Letters 404(4-6):309-314.

[2] Zhang S, Yu X, Li F, Kang G, Chen L, Zhang X (2012) Laser induced breakdown spectroscopy for local equivalence ratio measurement of kerosene/air mixture at elevated pressure. Optics and Lasers in Engineering 50(6):877-882.

[3] Ferioli F, Puzinauskas PV, Buckley SG (2002) LIBS for real-time equivalence ratio measurements in a spark-ignited engine. Laser Induced Plasma Spectroscopy and Applications (Optical Society of America), , p ThE23.

[4] Tripathi M, Srinivasan K, Krishnan S, Yueh F, Singh J (2013) A comparison of multivariate libs and chemiluminescence-based local equivalence ratio measurements in premixed atmospheric methane-air flames. Fuel 106:318-326.

[5] Han D, Steeper R (2002) An LIF equivalence ratio imaging technique for multicomponent fuels in an ic engine. Proceedings of the Combustion Institute 29(1):727-734.

[6] Falkenstein-Smith R, Sung K, Chen J, Harris K, Hamins A (2021) The Structure of Medium-Scale Pool Fires, Second Edition (National Institute of Standards and Technology, Gaithersburg, MD, USA), NIST Technical Note 2082,e2.

[7] Falkenstein-Smith R, Sung K, Chen J, Hamins A (2021) The chemical structure of a $30 \mathrm{~cm}$ methanol pool fire. Fire and Materials 45(3):429-434.

[8] Falkenstein-Smith R, Sung K, Chen J, Hamins A (2020) Chemical structure of medium-scale liquid pool fire. Fire Safety Journal :103099.

[9] Falkenstein-Smith R, Harris K, Sung K, Liang T, Hamins A (2021) A calibration and sampling technique for quantifying the chemical structure in fires using GC/MSD analysis. Fire and Materials .

[10] Babrauskas V, Parker W, Mulholland G, Twilley W (1994) The phi meter: A simple, fuel-independent instrument for monitoring combustion equivalence ratio. Review of scientific instruments 65(7):2367-2375.

[11] Andersson B, Babrauskas V, Holmstedt G, Särdqvist S, Winter G (1997) Scaling of combustion products: Initial results from the TOXFIRE study. Industrial Fires III Workshop Proceedings, , pp 65-74.

[12] Chen N (2012) Smoke Explosion in Severally Ventilation Limited Compartment Fires Master's thesis University of Canterbury, Christchurch, New Zealand.

[13] Parkes A (2009) The Impact of Size and Location of Pool Fires on Compartment Fire Behaviour. Ph.D. thesis. University of Canterbury, Christchurch, New Zealand, .

[14] Lonnermark A, Babrauskas V (1996) Toxfire-fire characteristics and smoke gas analyses in under-ventilated large-scale combustion experiments (SP Swedish National Testing and Research Institute, Borås, Sweden), SP Report 1996:46.

[15] Blomqvist P, Lönnermark A (2001) Characterization of the combustion products in large-scale fire tests: comparison of three experimental configurations. Fire and $\mathrm{Ma}$ terials 25(2):71-81. 
[16] Andersson B, Markert F, Holmstedt G (2005) Combustion products generated by hetero-organic fuels on four different fire test scales. Fire Safety Journal 40(5):439465.

[17] Purser D, Purser J (2008) HCN yields and fate of fuel nitrogen for materials under different combustion conditions in the iso 19700 tube furnace and large-scale fires. Fire Safety Science 9:1117-1128.

[18] Wieczorek C, Vandsburger U, Floyd J (2004) Evaluating the global equivalence ratio concept for compartment fires: Part II-limitations for correlating species yields. Journal of Fire Protection Engineering 14(3):175-197.

[19] Pitts W (1995) The global equivalence ratio concept and the formation mechanisms of carbon monoxide in enclosure fires. Progress in energy and combustion science 21(3):197-237.

[20] Forell B (2007) A methodology to assess species yields of compartment fires by means of an extended global equivalence ratio concept, .

[21] Richter H, Lorenz W, Bahadir M (1999) The global equivalence ratio concept in laboratory scale combustion experiments. Chemosphere 39(4):555-562.

[22] Pitts W (1994) Global equivalence ratio concept and the prediction of carbon monoxide formation in enclosure fires (National Institute of Standards and Technology, Gaithersburg, MD, USA), NIST Monograph 179.

[23] Andersson B, Holmstedt G, Dagneryd A (2003) Determination of the equivalence ratio during fire, comparison of techniques. Fire Safety Science 7:295-308.

[24] Brown C, Falkenstein-Smith R, Cleary T (2022) Reduced-Scale Compartment Gaseous Fuels Backdraft Experiments (National Institute of Standards and Technology, Gaithersburg, MD, USA), NIST Technical Note 2183. 


\section{A. Photos of constructed second-generation phi meter}

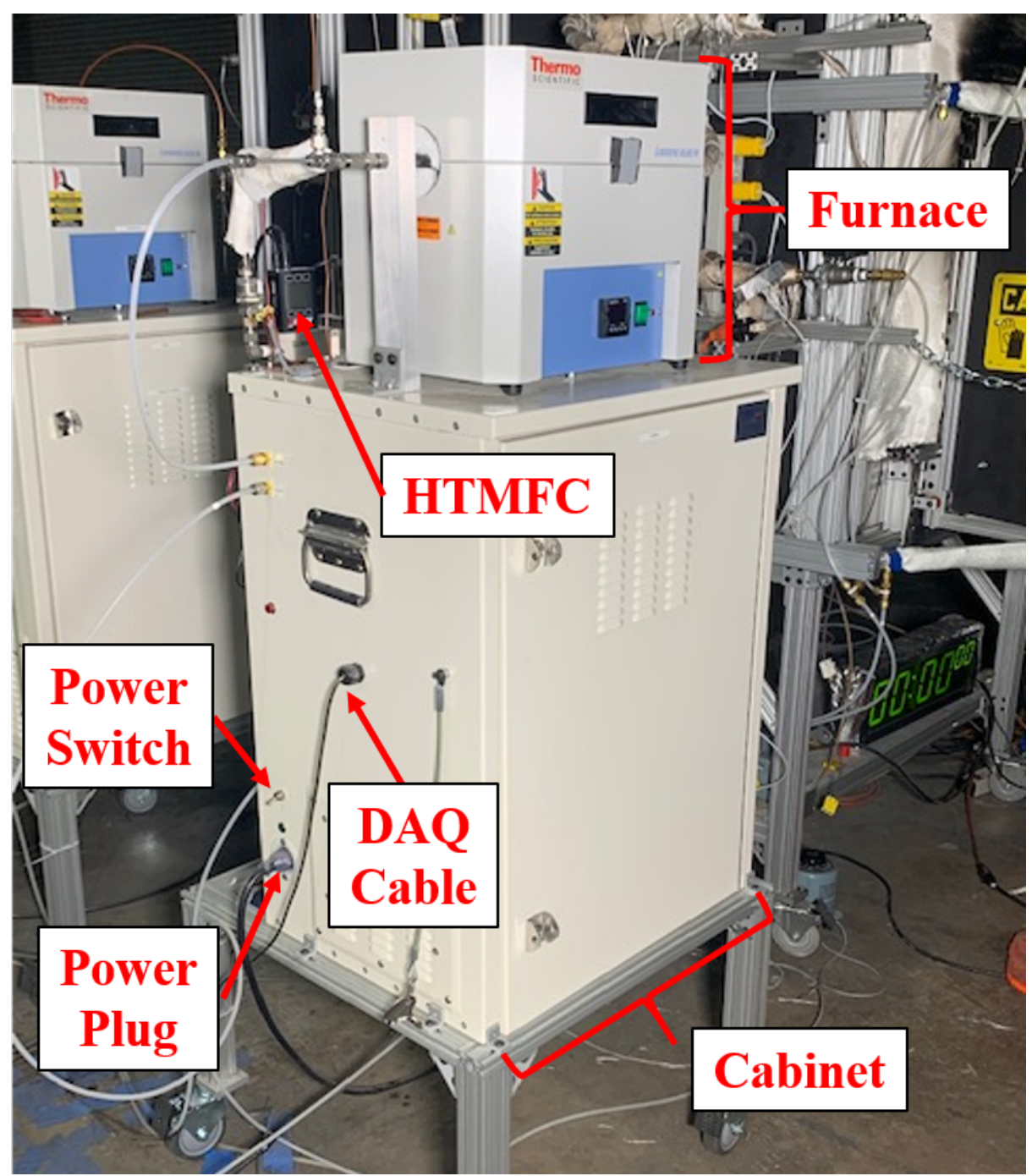

Fig. A.1. Front and side view photograph of the second-generation phi meter. 


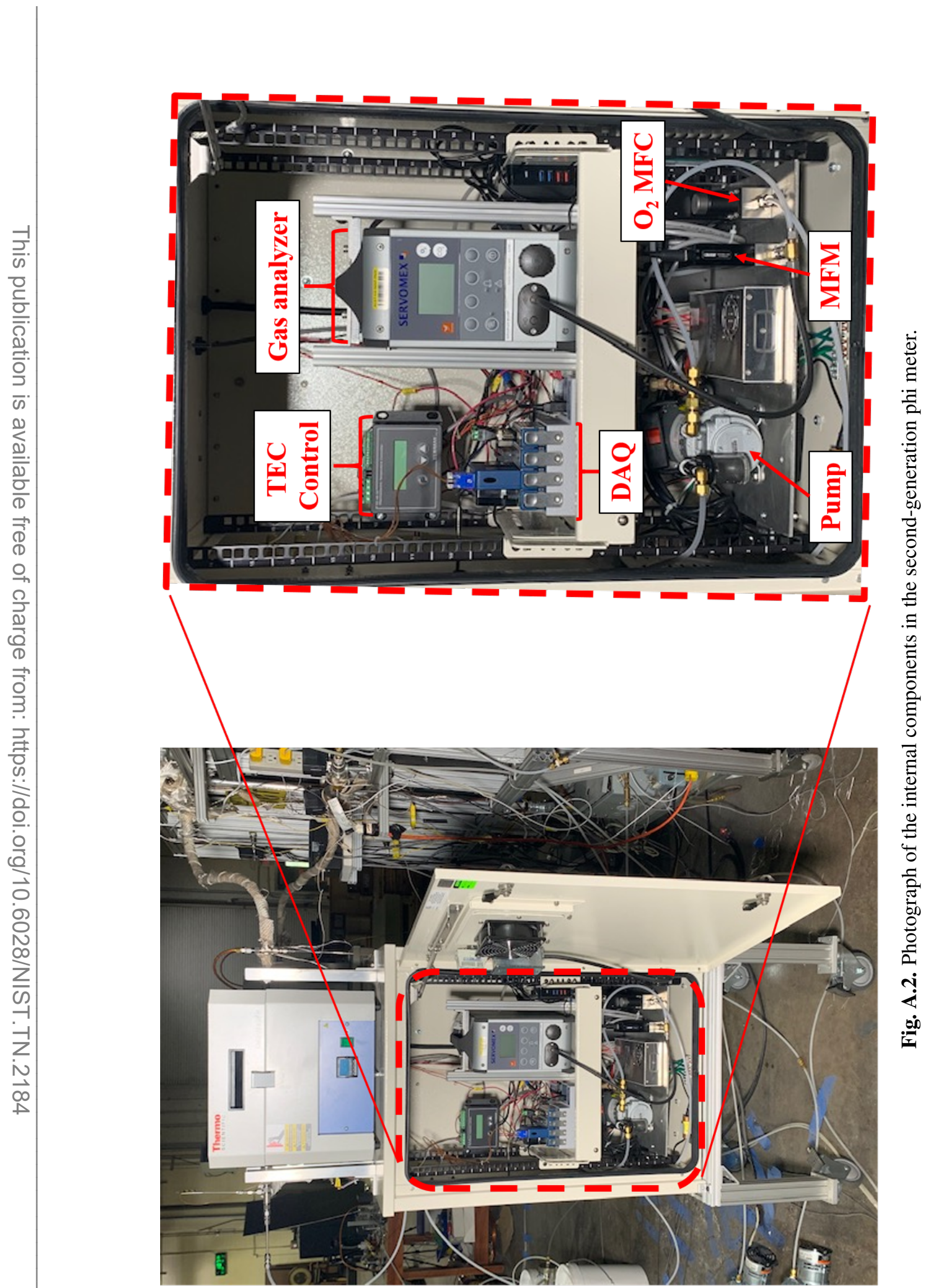



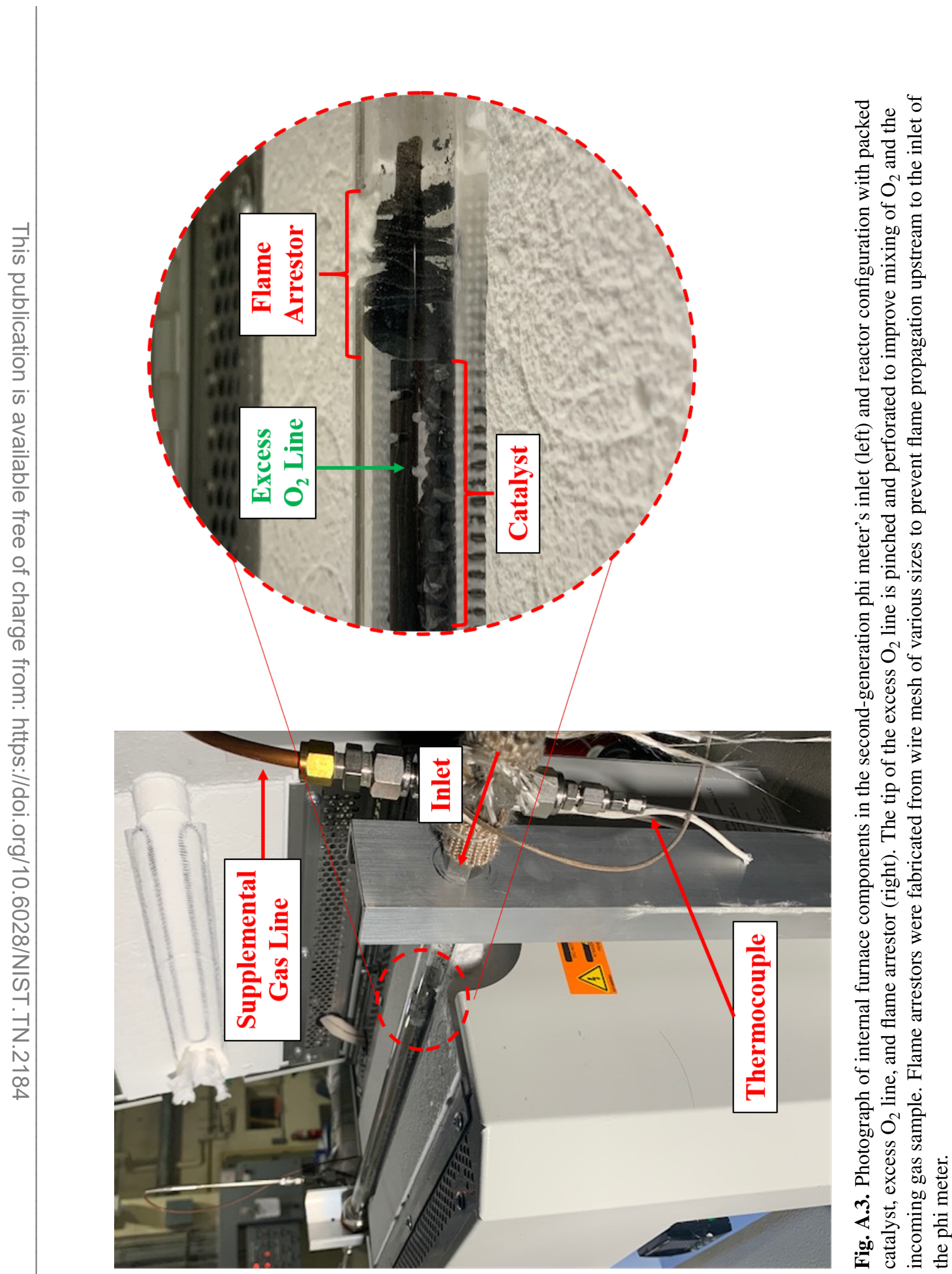


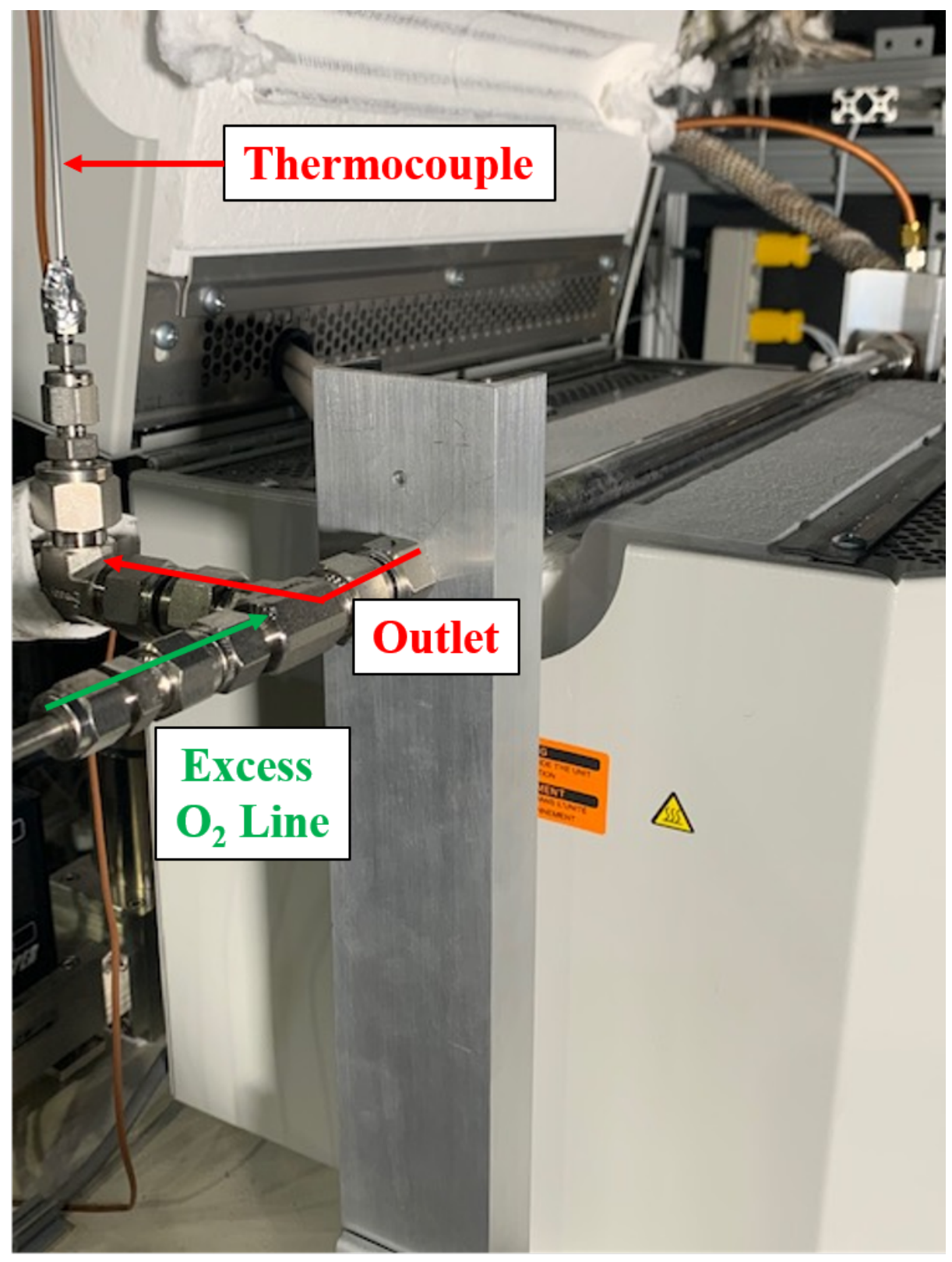

Fig. A.4. Side view photograph of components in the second-generation phi meter's outlet. 


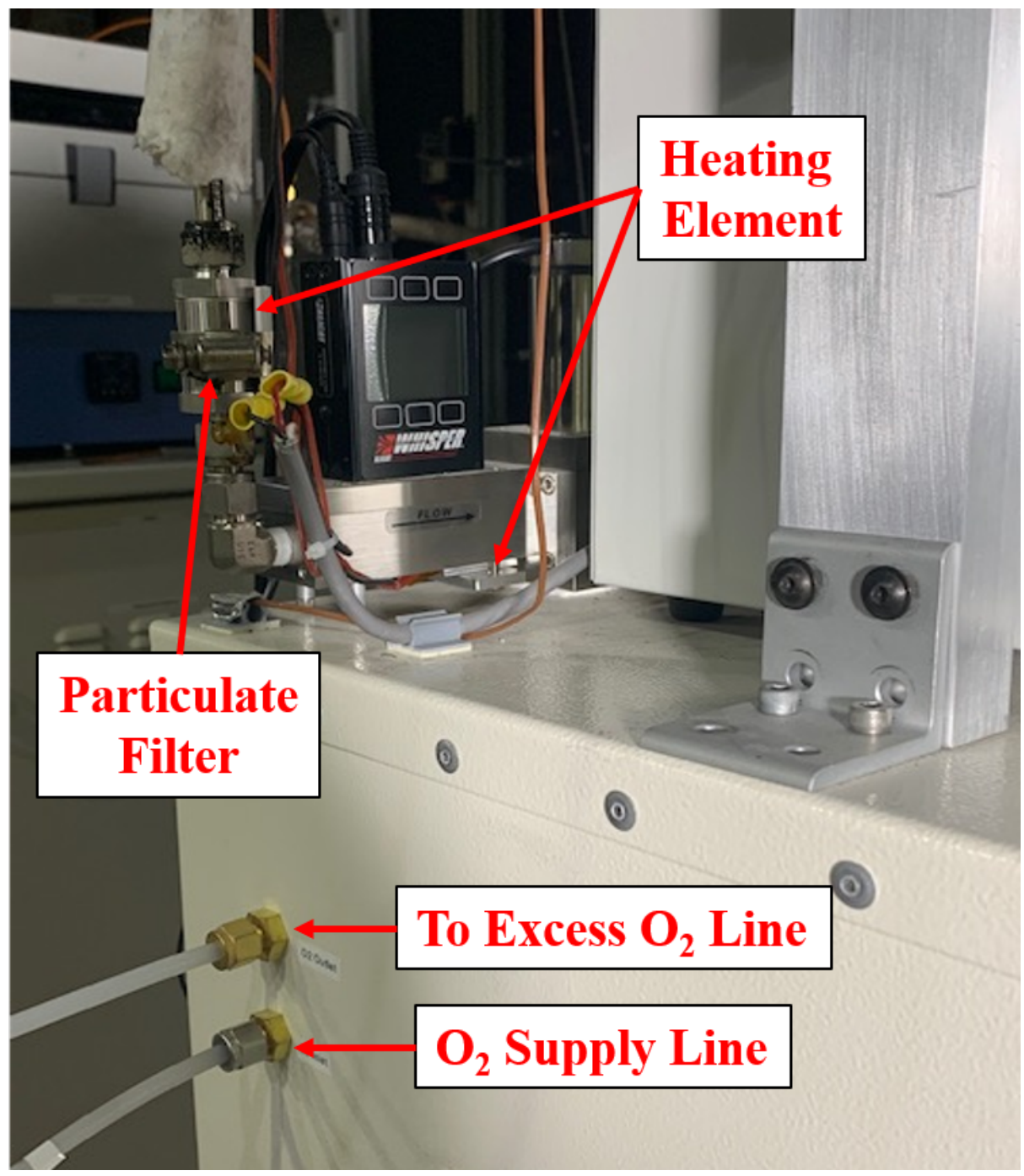

Fig. A.5. Photograph of the components used to heat and mitigate potential particulate contamination of the high-temperature mass flow controller. The ports for the $\mathrm{O}_{2}$ supply and excess line are also shown. 


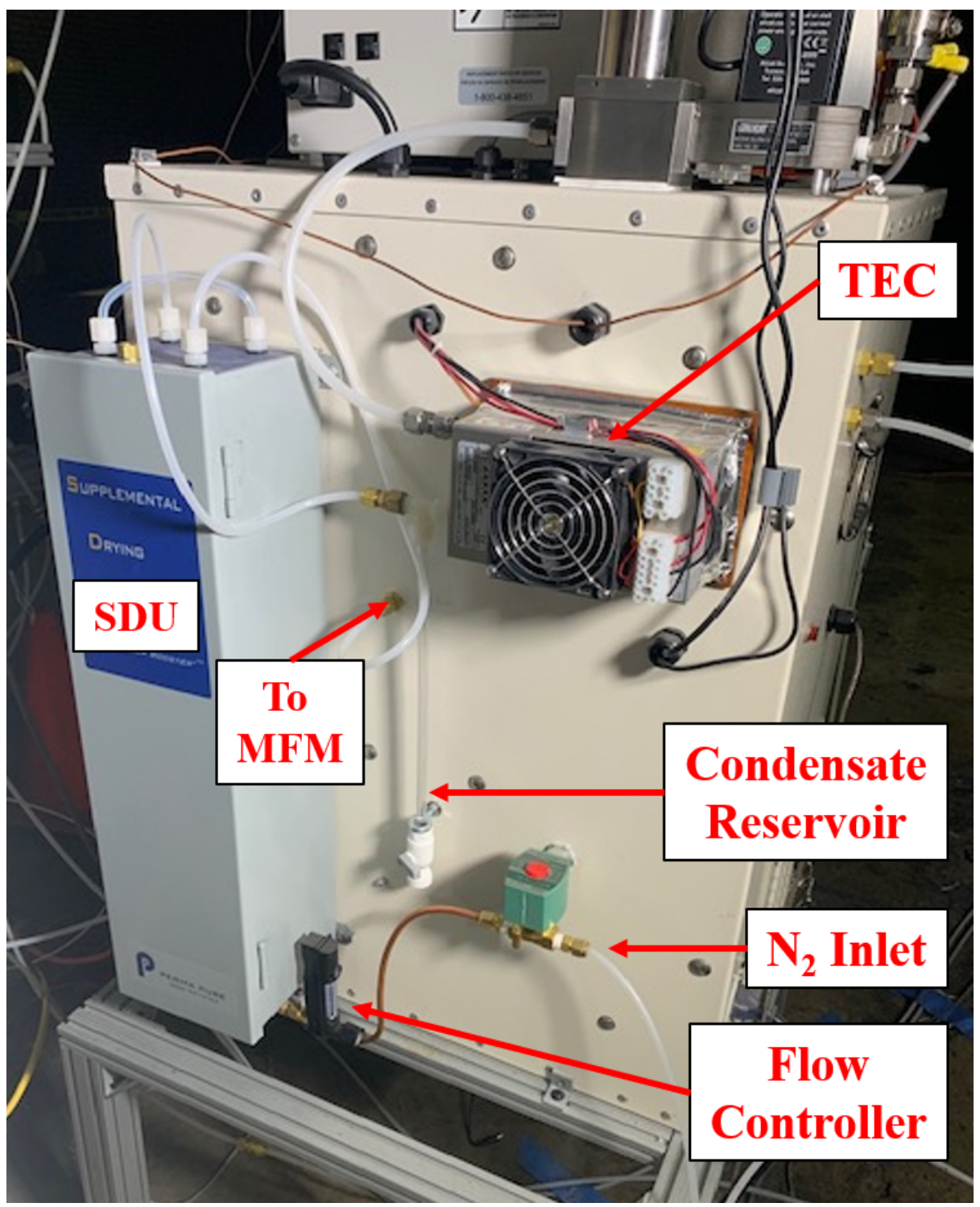

Fig. A.6. Rear view photograph of the second-generation phi meter. The supplemental drying unit (SDU) requires $\mathrm{N}_{2}$ input to produce an internal counterflow on the outer side of the incorporated Nafion tube that aids in drying the sample input. 


\section{B. Uncertainty Analysis of Second-Generation Phi Meter Measurements}

\section{B.1 Global Equivalence Ratio}

As shown in in Eq. 10, real-time measurements of the global equivalence ratio, $\phi_{\mathrm{G}}$, is determined from a combination of the volumetric flow reading of the dried exhaust stream, $\dot{V}_{\mathrm{MFM}}$, the $\mathrm{O}_{2}$ and $\mathrm{CO}_{2}$ concentrations within the dried exhaust stream, $X_{\mathrm{O}_{2}, \mathrm{~A}}$ and $X_{\mathrm{CO}_{2}, \mathrm{~A}}$, and the volumetric flow of excess oxygen introduced in the phi meter's reactor, $\dot{V}_{\mathrm{O}_{2} \text {, Ex }}$. The uncertainty of the global equivalence ratio is estimated using the law of propagation of uncertainty:

$u_{\phi_{\mathrm{G}}}=\sqrt{\left(\frac{\partial \phi_{\mathrm{G}}}{\partial \dot{V}_{\mathrm{MFM}}} u_{\dot{\mathrm{V}}_{\mathrm{MFM}}}\right)^{2}+\left(\frac{\partial \phi_{\mathrm{G}}}{X_{\mathrm{O}_{2}, \mathrm{~A}}} u_{\mathrm{X}_{\mathrm{O}_{2}, \mathrm{~A}}}\right)^{2}+\left(\frac{\partial \phi_{\mathrm{G}}}{\partial X_{\mathrm{CO}_{2}, \mathrm{~A}}} u_{\mathrm{CO}_{2}, \mathrm{~A}}\right)^{2}+\left(\frac{\partial \phi_{\mathrm{G}}}{\dot{V}_{\mathrm{O}_{2}, \mathrm{Ex}}} u_{\dot{V}_{\mathrm{O}_{2}, \mathrm{Ex}}}\right)^{2}}$

The volume fraction of oxygen in the air, $X_{\mathrm{O}_{2} \text {,Ent, }}$ is included in Eq. 10 and is assumed to be constant, and therefore does not affect the global equivalence ratio uncertainty. A coverage factor of 2 is applied to the combined uncertainty to produce a $95 \%$ confidence interval.

The uncertainty of the concentration and flow measurements in Eq. B.1 are defined as the Type B evaluation of standard uncertainty, determined from the instrument error provided by the manufacturer. Table B.1 provides a summary of instruments incorporated into the phi meter that are used to determine $\phi_{\mathrm{G}}$.

Table B.1. List of uncertainties for selected phi meter components.

\begin{tabular}{llc}
\hline Components & Manufacturer & Rel. Uncertainty (\%) \\
\hline High-Temperature Mass Flow Controller & Alicat Scientific, Inc. & 0.2 \\
Oxygen Mass Flow Controller & Brooks Instrument & 2.0 \\
Mass Flow Meter & Alicat Scientific, Inc. & 0.2 \\
Paramagnetic $\mathrm{O}_{2}$ Sensor & Servomex Group Ltd. & 0.5 \\
$\mathrm{NDIR} \mathrm{CO}_{2}$ Sensor & Servomex Group Ltd. & 4.0 \\
\hline
\end{tabular}

A time-averaged global equivalence ratio is calculated when the phi meter's extracted gas sample is assumed to be a homogeneous mixture. The uncertainty of time-averaged global equivalence ratio measurements is estimated from a combination of the Type A and $B$ evaluations of standard uncertainty. The Type A evaluation of standard uncertainty is defined as the standard deviation of the measurements taken over the averaging period, $s_{\phi_{\mathrm{G}}}$. The Type B evaluation of standard uncertainty is determined using Eq. B.1, as previously described. The combined uncertainty is calculated via quadrature:

$$
u_{\bar{\phi}_{\mathrm{G}}}=\sqrt{u_{\phi_{\mathrm{G}}}^{2}+s_{\phi_{\mathrm{G}}}^{2}}
$$




\section{B.2 Water Vapor Flow in the Reactor's Exhaust}

The portion of water vapor in the phi meter reactor's exhaust flow is determined from the difference between the flow measurements at the high-temperature mass flow controller and mass flow meter. The uncertainty of the volumetric flow of water vapor is estimated using the law of propagation of uncertainty:

$$
u_{\dot{V}_{\mathrm{H}_{2} \mathrm{O}}}=\sqrt{\left(\frac{\partial \dot{V}_{\mathrm{H}_{2} \mathrm{O}}}{\partial \dot{V}_{\mathrm{O}_{2}, \text { Inlt }}} u_{\dot{V}_{\mathrm{HTMFC}}}\right)^{2}+\left(\frac{\partial \dot{V}_{\mathrm{H}_{2} \mathrm{O}}}{\dot{V}_{\mathrm{O}_{2}, \mathrm{Ex}}} u_{\dot{\mathrm{V}}_{\mathrm{MFM}}}\right)^{2}}
$$

The uncertainty of the real-time high-temperature mass flow controller and mass flow meter measurements is estimated for the Type B evaluation of standard uncertainty defined in Table B.1.

The time-averaged volumetric flow of water vapor is calculated from a combination of the Type A and B evaluations of standard uncertainty, assuming a homogeneous steady mixture. The Type A evaluation of standard uncertainty is defined as the standard deviation of the measurements taken over the averaging period, $s_{\dot{V}_{\mathrm{H}_{2} \mathrm{O}}}$. The Type B evaluation of standard uncertainty is determined using Eq. B.3. The combined uncertainty is calculated via quadrature:

$$
u_{\bar{V}_{\mathrm{H}_{2} \mathrm{O}}}=\sqrt{u_{\dot{\mathrm{V}}_{\mathrm{H}_{2} \mathrm{O}}}^{2}+s_{\dot{\mathrm{V}}_{\mathrm{H}_{2} \mathrm{O}}}^{2}}
$$

\section{B.3 Carbon to Hydrogen Ratio}

The carbon to hydrogen ratio is calculated using Eq. 12 that incorporates the volume fraction of $\mathrm{CO}_{2}$ and $\mathrm{H}_{2} \mathrm{O}$ in the phi meter reactor's exhaust.

$$
u_{\mathrm{C} / \mathrm{H}}=\frac{\mathrm{W}_{\mathrm{C}}}{\mathrm{W}_{\mathrm{H}}} \sqrt{\left(\frac{\partial(\mathrm{C} / \mathrm{H})}{\partial X_{\mathrm{CO}_{2}}} u_{\mathrm{XO}_{2}}\right)^{2}+\left(\frac{\partial(C / H)}{\partial X_{\mathrm{H}_{2} \mathrm{O}}} u_{\mathrm{X}_{\mathrm{H}_{2} \mathrm{O}}}\right)^{2}}
$$

The uncertainty of the $\mathrm{CO}_{2}$ and $\mathrm{H}_{2} \mathrm{O}$ measurements is described in Appendix B.1 and B.2, respectively.

\section{B.4 Mass Balance}

The uncertainty of time-averaged total mass flow rate estimated in the bench-scale experiments is determined from the law of propagation of uncertainty.

$$
u_{\dot{m}_{\mathrm{tot}}}=\sqrt{\sum u_{\dot{m}_{\mathrm{i}}}^{2}}
$$

The uncertainty of an individual species' time-averaged mass flow rate is determined from the combined Type A and B evaluation of standard uncertainty. The Type A and B evaluation of standard uncertainty is defined as the standard deviation of averaged measurements and the reported bias in the instrumentation, respectively. Time-averaged mass flow rates are calculated from steady-state measurements, indicating that the dominant contributor to the uncertainty of the total mass flow rate is the Type B evaluation of standard uncertainty. 


\section{B.5 Local Equivalence Ratio}

Real-time measurements of the local equivalence ratio are calculated via Eq. 17, which incorporates $\mathrm{O}_{2}$ and $\mathrm{N}_{2}$ concentrations measurements in the phi-meter's extracted gas sample, $X_{\mathrm{O}_{2}, \text { In }}$ and $X_{\mathrm{N}_{2}, \text { In }}$, and dried reactor's exhaust, $X_{\mathrm{O}_{2}, \mathrm{~A}}$ and $X_{\mathrm{N}_{2}, \mathrm{~A}}$, and the volumetric flow rate measurements of the excess oxygen introduced at the inlet of the phi meter's reactor and nitrogen in dried reactor's exhaust, $\dot{V}_{\mathrm{ex}}$ and $\dot{V}_{\mathrm{N}_{2}, \mathrm{MFM}}$, respectively. The uncertainty of the local equivalence ratio is estimated from the law of propagation of uncertainty:

$$
\begin{aligned}
u_{\phi_{\mathrm{L}}}= & {\left[\left(\frac{\partial \phi_{\mathrm{L}}}{\partial X_{\mathrm{N}_{2}, \mathrm{In}}} u_{X_{\mathrm{N}_{2}, \text { In }}}\right)^{2}+\left(\frac{\partial \phi_{\mathrm{L}}}{X_{\mathrm{O}_{2}, \mathrm{In}}} u_{\mathrm{O}_{2}, \mathrm{In}}\right)^{2}+\left(\frac{\partial \phi_{\mathrm{L}}}{\partial \dot{V}_{\mathrm{ex}}} u_{\dot{\mathrm{V}}_{\mathrm{ex}}}\right)^{2}\right.} \\
& \left.+\left(\frac{\partial \phi_{\mathrm{L}}}{\partial \dot{V}_{\mathrm{N}_{2}, \mathrm{MFM}}} u_{\dot{\mathrm{V}}_{2}, \mathrm{MFM}}\right)^{2}+\left(\frac{\partial \phi_{\mathrm{L}}}{\partial X_{\mathrm{O}_{2}, \mathrm{~A}}} u_{X_{\mathrm{O}_{2}, \mathrm{~A}}}\right)^{2}+\left(\frac{\partial \phi_{\mathrm{L}}}{\partial X_{\mathrm{N}_{2}, \mathrm{~A}}} u_{{\mathrm{N}_{2}, \mathrm{~A}}_{1}}\right)^{2}\right]^{\frac{1}{2}}
\end{aligned}
$$

The uncertainty of the oxygen concentration measurements and volumetric flow rate are estimated from the Type B evaluation of standard uncertainty, reported in B.1. Indirect $\mathrm{N}_{2}$ flow rate and concentration uncertainties are calculated via the law of propagation of uncertainty. 


\section{Derivation of Local Equivalence Ratio Measurement via Phi Meter}

An extracted sample introduced into the phi meter may consist of various quantities of uncombusted fuel and oxygen, intermediate species, combustion products and inert gases. When sampled into a phi meter, an excess molar flow of oxygen, $\dot{A}$, is introduced to an extracted gas sample, creating a lean combustion that consumes all uncombusted fuel.

$$
\begin{gathered}
\dot{\mathrm{a}} \mathrm{C}_{\mathrm{x}} \mathrm{H}_{\mathrm{y}} \mathrm{O}_{\mathrm{z}} \mathrm{N}_{\alpha}+\dot{\mathrm{b}} \mathrm{CO}_{2}+\dot{\mathrm{c}} \mathrm{H}_{2} \mathrm{O}+\dot{\mathrm{d}}\left(\mathrm{O}_{2}+3.74 \mathrm{~N}_{2}+0.0445 \mathrm{Ar}\right)+\dot{\mathrm{e}} \mathrm{CO}+\dot{\mathrm{f}} \mathrm{H}_{2}+\dot{\mathrm{A}} \mathrm{O}_{2} \rightarrow \\
\dot{\mathrm{B}} \mathrm{CO}_{2}+\dot{\mathrm{C}} \mathrm{H}_{2} \mathrm{O}+\dot{\mathrm{D}} \mathrm{O}_{2}+\dot{\mathrm{E}} \mathrm{N}_{2}+\dot{\mathrm{F}} \mathrm{Ar}
\end{gathered}
$$

where

$$
\begin{gathered}
\dot{\mathrm{B}}=\dot{\mathrm{a}} \mathrm{x}+\dot{\mathrm{b}}+\dot{\mathrm{e}} \\
\dot{\mathrm{C}}=\frac{1}{2}(\dot{\mathrm{a}} \mathrm{y})+\dot{\mathrm{c}}+\dot{\mathrm{f}} \\
\dot{\mathrm{D}}=\frac{1}{2}(\dot{\mathrm{a}} \mathrm{z}+2 \dot{\mathrm{b}}+\dot{\mathrm{c}}+2 \dot{\mathrm{d}}+\dot{\mathrm{e}}+2 \dot{\mathrm{A}}-2 \dot{\mathrm{B}}-\dot{\mathrm{C}})
\end{gathered}
$$

Through a combination of Eqs. C.2-C.4, Eq. C.4 can be reconfigured and simplified to:

$$
\frac{\dot{\mathrm{D}}-\dot{\mathrm{A}}}{\dot{\mathrm{d}}}=1-\frac{2 \dot{\mathrm{a}}\left(\mathrm{x}+\frac{\mathrm{y}}{4}-\frac{\mathrm{z}}{2}\right)+\dot{\mathrm{e}}+\dot{\mathrm{f}}}{2 \dot{\mathrm{d}}}
$$

Recognizing that the ratio on the right hand side of Eq. C.5 is defined as $1-\phi_{\mathrm{L}}$ from Eq. 18 , Eq. C.5 can be rearranged to:

$$
\phi_{\mathrm{L}}=1+\frac{\dot{\mathrm{A}}-\dot{\mathrm{D}}}{\dot{\mathrm{d}}}
$$

In the context of the phi meter, $\dot{\mathrm{D}}$ is the portion of oxygen in the total molar flow at the outlet of the phi meter, and $\dot{d}$ is the molar flow of oxygen in the extracted sample at the inlet of the phi meter. Therefore, Eq. C.6 can be refined based on exiting measurements in the gas sampling setup of the backdraft experiment:

$$
\phi_{\mathrm{L}}=1+\frac{\left(X_{\mathrm{O}_{2}, \mathrm{Ex}} \cdot \dot{V}_{\mathrm{in}}\right)-\left(X_{\mathrm{O}_{2}, \mathrm{~A}} \cdot \dot{V}_{\mathrm{MFM}}\right)}{\left(X_{\mathrm{O}_{2}, \mathrm{In}} \cdot \dot{V}_{\mathrm{in}}\right)}
$$

where $\dot{V}_{\text {in }}$ is the total number of moles at the inlet. Assuming that $\mathrm{N}_{2}$ acts as an inert gas as it passes through the phi meter's reactor, $\dot{V}_{\text {in }}$ and $\dot{X}_{\mathrm{O}_{2}, \text { In }}$ can be redefined on a nitrogen basis.

$$
\dot{V}_{\text {in }}=\left(\frac{X_{\mathrm{N}_{2}, \mathrm{~A}}}{X_{\mathrm{N}_{2}, \text { In }}}+\frac{\dot{V}_{\mathrm{ex}}}{\dot{V}_{\mathrm{MFM}}}\right)
$$

and

$$
\dot{X}_{\mathrm{O}_{2}, \text { In }}=\frac{X_{\mathrm{O}_{2}, \text { In }}}{X_{\mathrm{N}_{2}, \text { In }}} \cdot \frac{\dot{V}_{\mathrm{N}_{2}, \mathrm{MFM}}}{\dot{V}_{\text {in }}}
$$

Through a combination of Eq. C.8 and C.9, Eq. C.7 can be reconfigured to be:

$$
\phi_{\mathrm{L}}=1+\left(\frac{X_{\mathrm{N}_{2}, \text { In }}}{X_{\mathrm{O}_{2}, \text { In }}}\right)\left(\frac{\dot{V}_{\mathrm{ex}}}{\dot{V}_{\mathrm{N}_{2}, \mathrm{MFM}}}-\frac{X_{\mathrm{O}_{2}, \mathrm{~A}}}{X_{\mathrm{N}_{2}, \mathrm{~A}}}\right)
$$




\section{Uncertainty Analysis of Additional Gas Species Concentration Measurements}

Global and local equivalence ratio measurements are calculated from gas species measurements made from the gas analyzer and GC/MS analysis using Eqs. 16 and 18. Equivalence ratios uncertainties are estimated via the the law of propagation of uncertainty.

$$
u_{\phi_{\mathrm{G}}}=\sqrt{\sum\left(\frac{\partial \phi_{\mathrm{G}}}{\partial X_{\mathrm{i}}} u_{X_{i}}\right)^{2}}
$$

and

$$
u_{\phi_{\mathrm{L}}}=\sqrt{\sum\left(\frac{\partial \phi_{\mathrm{L}}}{\partial X_{\mathrm{i}}} u_{X_{i}}\right)^{2}}
$$

The uncertainty of individual gas species concentration measurements is estimated from the Type B evaluation of standard uncertainty defined by the bias in the instrumentation. For direct gas analyzer measurements, the uncertainty attributed to the instrument is provided in Table D.1. Uncertainties of gas species concentration estimated from gas analyzer measurements (i.e., fuel, $\mathrm{N}_{2}$, and $\mathrm{H}_{2} \mathrm{O}$ ) are calculated via the law of propagation of uncertainty. The uncertainties of gas species concentrations measurements obtained from GC/MS analysis are calculated using the methods described in Ref. [6].

Table D.1. List of uncertainties for gas analyzer components.

\begin{tabular}{llc}
\hline Components & Manufacturer & Rel. Uncertainty (\%) \\
\hline Paramagnetic $\mathrm{O}_{2}$ Sensor & California Analytical Instruments, Inc. & 2.0 \\
$\mathrm{NDIR} \mathrm{CO}_{2}$ Sensor & California Analytical Instruments, Inc. & 4.0 \\
\hline
\end{tabular}

